Article

\title{
Interrelations among Leadership Competencies of BIM Leaders: A Fuzzy DEMATEL-ANP Approach
}

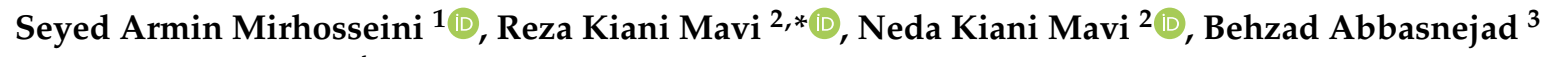 \\ and Farzaneh Rayani ${ }^{4}$ \\ 1 School of Civil Engineering, Iran University of Science and Technology (IUST), Tehran, Iran; \\ arminmirhoseiny@gmail.com \\ 2 School of Business and Law, Edith Cowan University (ECU), 270 Joondalup Drive, Joondalup, WA 6027, \\ Australia; n.kianimavi@ecu.edu.au \\ 3 School of Property, Construction and Project Management, RMIT University, Melbourne, VIC 3000, \\ Australia; behzad.abbasnejad@rmit.edu.au \\ 4 School of Urban Designing, Islamic Azad University (IAU), Kerman Branch, Kerman, Iran; \\ rayanifarzaneh@gmail.com \\ * Correspondence: r.kianimavi@ecu.edu.au
}

Received: 3 August 2020; Accepted: 17 September 2020; Published: 22 September 2020

\begin{abstract}
The use of new, digitally enabled innovations, such as building information modeling (BIM), raises issues such as the delineation of a competent leader. Even though BIM-based competency assessment models have become essential tools for maximizing the potential values of BIM implementation, the current competency models provide limited focus on leadership aspects that facilitate and enhance the BIM implementation efforts. This paper seeks to identify the specific competencies required for BIM implementation and examines the relationships between these competencies. Thirty-two experts from around the globe investigated a total of 15 leadership competencies under three categories pertaining to intellectual, managerial, and emotional leadership. Fuzzy Decision-Making Trial and Evaluation Laboratory (DEMATEL) was implemented to examine the cause-and-effect relationships among the BIM leadership competencies and fuzzy analytic network process (ANP) was performed to weigh those competencies. Findings show that the intellectual competencies act as the cause group, while managerial and emotional competencies are the effect groups. Moreover, the involving leadership is found to be the more suitable leadership style for BIM professionals, given the current capability and maturity levels of BIM implementation, in order to deal with the required changes throughout the BIM implementation process. This study contributes to the existing body of knowledge in the BIM domain to examine the associated leadership competencies by using the multi-criteria decision-making (MCDM) technique. The results of this research show the relative importance of criteria and sub-criteria, which contributes to further improvement of BIM leadership.
\end{abstract}

Keywords: building information modeling (BIM); BIM leader; leadership competencies; fuzzy DEMATEL; fuzzy ANP

\section{Introduction}

Building information modeling (BIM) is one of the current architecture, engineering, and construction (AEC) industry innovations, and its proliferation has led to the emergence of a range of new roles and responsibilities [1,2]. Nowadays, BIM is usually integrated with other technologies to enhance performance and obtain a greater variety of industry benefits. For instance, integrating extended reality (ER) with a BIM approach assists practitioners to improve their project 
management processes in a number of ways. These include the location of any design flaws before implementation, the development of a greater understanding of change orders and requests for information, and the delineation of approaches for effectively linking BIM to ER tools, such as virtual reality (VR) cameras [3,4]. Reality-capturing tools can also be integrated with BIM models to obtain further industry benefits. Identifying as-is building objects through the application of an image-driven system [5] and realizing as-built defects in prefabricated components by implementation of a BIM laser scanning system [6] are two outcomes of this integration. These approaches underpin future education and training of architects and engineers alike [7].

A deficient BIM-related skill set negatively influences its implementation in projects [8], therefore, professionals adept across BIM processes are in high demand [9]. BIM practitioners must ultimately possess competencies such as technological, managerial, and soft skills [8,10]. Although the definition of BIM-related roles, skills, and competencies has been disputed among BIM experts, recruiters [9], and non-BIM experts alike [11], there is consensus that leadership is an essential skill for BIM practitioners [12].

Leadership has been studied more than other human behaviors [13]. It is considered a significant skill and a soft success factor for project managers across a variety of industries [14-16], and its competencies are crucial to the successful performance of businesses, projects, and organizations [17]. Specifically, leadership competencies are directly linked to successful innovation implementation and project success and thereby contribute to providing a better return on investment (ROI) [18]. According to [19], "leaders should be able to establish and maintain vision, strategy, and communication throughout the project by influencing, guiding, monitoring, and evaluating the performance of their team". Though Tett et al. in [20] associated leadership as one part of managers' duties, it is nevertheless important to note that leadership itself has its own competencies. Previous studies have endeavored to introduce and categorize leadership styles and competencies from different perspectives such as authentic leadership by [21] and six leadership schools by [17]. Dulewicz and Higgs in [13] presented the last leadership school (the competency school), which encompasses 15 different leadership competencies as well as three leadership styles. Many competencies have been introduced in earlier studies [13,17,22]; however, as Alvarenga et al. suggested in [14], these should be curtailed to the most crucial selection to assist leaders to focus on the core competencies that improve the innovation implementation and project performances.

BIM leadership competencies refer to the knowledge, skills, abilities, experience, and attributes that a particular BIM leader needs to possess and/or develop for BIM adoption and implementation. However, the lack of a BIM specialist with the required competencies [9] presents a major challenge to this process. Identifying and assessing BIM competencies produces myriad benefits such as performance improvement, supporting training and professional development as well as certification and accreditation [12]. Despite extensive research efforts into leadership, little information is available on the importance of leadership competencies and their contribution to the BIM domain. Specific BIM-related roles demand specific competencies [19], and an improper allocation of skills and competencies can contribute to implementation failure [17]. As leadership competencies are acquisitive [17], BIM training centers can include leadership competencies and other BIM-related skills deemed paramount for BIM professionals in their curricula $[9,18]$.

Leadership competencies are inevitably dependent and intertwined [16,23,24]. BIM implementation is, moreover, a complex process, and its influential factors are in constant change. Therefore, a dynamic perspective of leadership competencies provides an enhanced understanding of their cause-and-effect relationships and what competencies should be prioritized in a BIM implementation process. Finding substantial leadership competencies and their interrelations can assist BIM governors, organizations, and practitioners to develop their competencies more systematically and decrease the probability of BIM implementation failure.

There are several data analysis approaches, including data analytics techniques, that draw on machine learning mechanisms to analyze different data. As machine learning models are incapable of 
explaining predictions, and there are issues related to imbalanced data sets [25], using a method that relies on expert judgments was preferred in this research. As there are different clusters for leadership competencies, a multi-criteria decision-making (MCDM) approach was suitable for their evaluation. MCDM techniques are commonly employed to structure and solve complex decision-making problems when alternatives are available [26]. Leadership competencies are not completely independent and a combination of various competencies is what ultimately contributes to a leader's success. Since many competency models do not specifically identify the interactions among leadership competencies [27] and, further, given the dynamic nature of the BIM implementation process, the DEMATEL method was utilized in this study to examine the relationships among leadership categories and their competencies. In some of the existing research, the interrelationships of competency factors are based on a qualitative approach wherein experts provide descriptions predicated on their past experience and knowledge, which commonly includes some degree of uncertainty. Since the fuzzy set theory can mathematically handle the inherent uncertainty and ambiguity of human judgment, utilizing fuzzy numbers may help researchers improve their decision-making process and achieve more rigorous results [28,29].

Knowledge of core leadership competencies can help BIM project practitioners and companies in realizing the benefits of BIM tool and workflow implementations. Hence, the fuzzy analytic network process (ANP) was also utilized to determine the priority weights of leadership competencies. Adopting a deductive approach, this research implements fuzzy DEMATEL and fuzzy ANP to achieve the following objectives:

- Identify and evaluate the leadership competencies for BIM implementation,

- Examine the relationships among the BIM leadership competencies,

- Prioritize the main BIM leadership competencies,

- Examine the application of leadership competencies for implementing BIM tools and concepts.

To achieve the abovementioned objectives, this research will answer the following research questions:

1. What are the main leadership competencies for BIM implementation?

2. What are the cause-and-effect relations among leadership competencies for BIM professionals using fuzzy DEMATEL?

3. What are the priority weights of these competencies with fuzzy ANP?

4. Which leadership style is more applicable in the BIM domain?

The remainder of this paper is organized as follows: Section 2 reviews the literature on building information modeling (BIM), its required skills, and leadership studies and findings. Section 3 introduces the research methodology, fuzzy DEMATEL, and fuzzy ANP. Sections 4 and 5 contain the empirical study, discussion of the results, and practical implications. Finally, Section 6 concludes the paper.

\section{Literature Review}

One of the primary challenges to BIM implementation is the selection of competent team members. While BIM leaders and managers tend to focus primarily on the technical and financial aspects of implementing BIM systems, the behavioral aspects involved in BIM implementation are a key consideration. BIM leadership aspects can be categorized into the three domains of: structural support, competent BIM leaders, and team member competencies and composition (key BIM leadership pillars). These aspects are depicted in Figure 1. Structural support deals with aspects such as organizational support, financial support as well as rewards and recognition [30]. Competent BIM leadership refers to the facilitating roles leaders can assume to empower and/or coach team members as well as to demonstrate transformational behaviors throughout the BIM implementation process. The third category includes the competency identification, acquisition, and assessment of individuals as well as team and group composition involved in BIM implementation by BIM leaders [12]. The literature review shows that, while aspects related to structural support and individual and team competences 
and composition have garnered the most attention, the BIM leadership domain has been relatively overlooked [30]. Therefore, this paper aims to discuss the identification and application of leadership competencies in the context of BIM implementation as a way of maximizing both the effectiveness of other team members and the overall benefits from BIM workflows.

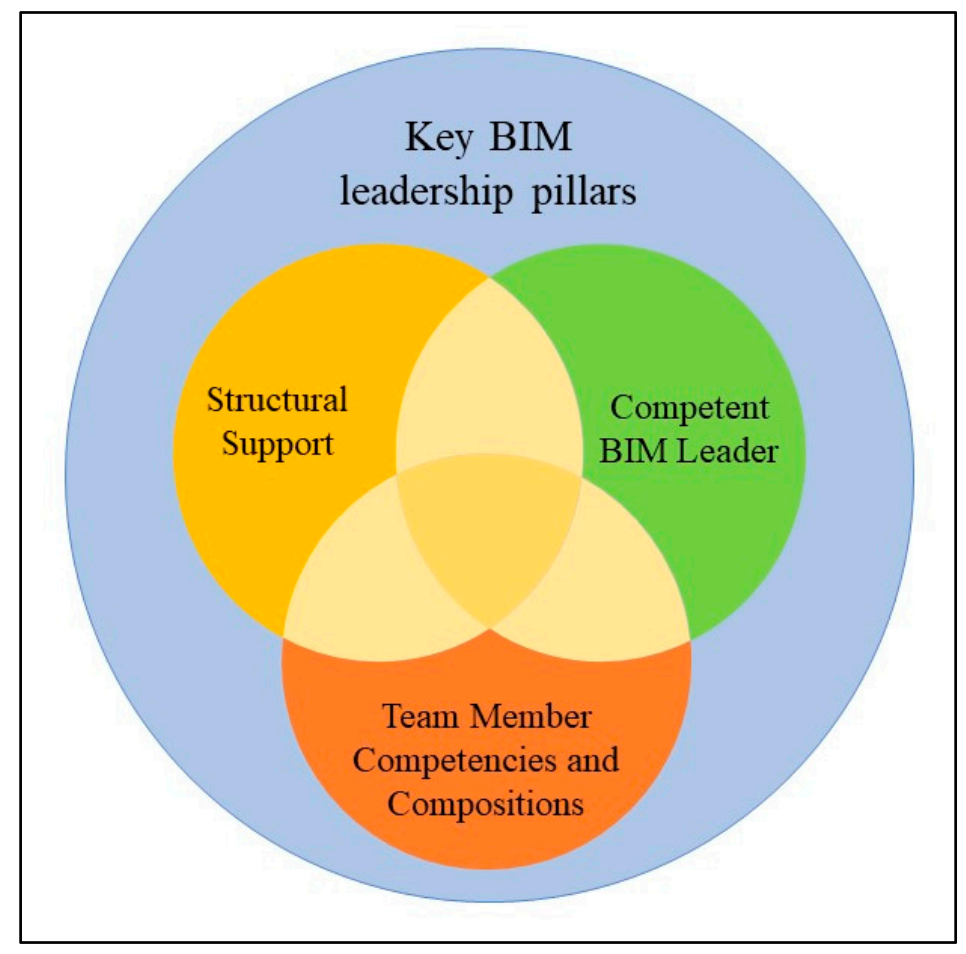

Figure 1. Building information modeling (BIM) leadership pillars.

\subsection{BIM Adoption and Implementation}

Adaptation of digitally enabled innovations and tools helps organizations and their leaders to reap a wealth of sustainable competitive advantages within the AEC industry [31]. The World Commission on Environment and Development (WCED) has appealed to the construction industry to implement sustainable practices into its ventures so that the vision of sustainable cities can be realized sooner rather than later [32,33]. The emergent green BIM trend within the AEC industry was described as a synergy between BIM and sustainability goals [33]. In the past, most design and construction professionals deemed sustainability an extraneous application of BIM [34]; however, BIM is increasingly utilized for sustainable construction practices nowadays [35]. The use of BIM in sustainable construction allows for the enhancement of project efficiency and productivity; ensures real-time sustainable design and multi-design alternatives; facilitates the selection of sustainable materials; reduces energy consumption, material wastage, and a project's environmental impact [33,35].

BIM is defined as "a set of interacting policies, processes and technologies that generate a methodology to manage the building design and project data in digital format throughout the building's life-cycle" [36]. BIM benefits the adopting companies by supporting innovation, developing new work practices, and creating more efficient construction projects [1]. Furthermore, the adaptation of BIM will enable the AEC companies to integrate fragmented contributors into their projects [37]. BIM is considered as a "system" innovation [2,38] as it consists of a set of interacting policies, processes, and technologies that work together in tandem throughout a built facility. According to [39], system innovations are the "integration of multiple independent innovations that must work together to perform new functions or improve the facility performance as a whole". System innovations substantially enhance overall productivity in the long term; however, they may require significant start-up costs and can change or eliminate the role of other members along the way. Implementing 
a system innovation requires subtler changes as the process entails a high degree of technological uncertainty and interface complexity, requiring participating companies to adjust their approaches in a coordinated manner [40]. Implementing BIM as a system innovation requires explicit and implicit collaboration to integrate emerging processes, policies, and technologies that will help to actualize the benefits from its workflows.

According to [41], BIM deployment at organizational and project levels must be implemented gradually. Further, Succar in [41] distinguished between capability stages and evolutionary steps. While stages are transformational changes, steps are incremental changes. BIM capability was defined as "the ability to perform a task or deliver a BIM service/product", which can be achieved through well-defined revolutionary stages separated by numerous evolutionary steps [2]. In Succar's model, the three capability stages, each with specific descriptions, are as follows:

- $\quad$ BIM stage 1: object-based modeling. BIM implementation is commenced by generating single-disciplinary models through "object-based 3D parametric software tools" such as Revit and ArchiCAD within the design, construction, or operation phase. There are no model-based interchanges between different disciplines. The collaboration at this stage is similar to pre-BIM status and only minor process change occurs at this stage. Communication is asynchronous and disjointed.

- BIM stage 2: model-based collaboration. Model-based collaboration may take place within one or between project phases. Communication between BIM players continues to be asynchronous, but pre-BIM delineation lines among roles, disciplines, and project phases diminish.

- BIM stage 3: network-based integration. Semantically integrated models (federated models) are created, shared, and maintained collaboratively across the project life cycle. Working around a unified and sharable model enhances collaboration and communication.

Each stage consists of the following evolutionary steps:

- Step A: from pre-BIM to BIM stage 1,

- Step B: from BIM stage 1 to BIM stage 2,

- Step C: from BIM stage 2 to BIM stage 3,

- Step D: from BIM stage 3 to post-BIM.

The collection of steps involved in working toward or within a BIM stage is driven by different perquisites, barriers within, and deliverables of each BIM stage [36]. For instance, in the first and second stages of BIM capability, communication is still asynchronous and disjointed. As such, it is likely that the success of BIM implementation rests on individual leaders actively facilitating communication and collaboration among the involved members. This is illustrated by [42] through a case study approach, suggesting that even with the introduction of BIM, construction projects rely on individual leadership to hold the people together and inspire collaboration. Further, it is argued by [43] that a BIM-enabled project without collaboration is doing nothing but "scratching the surface". Strong leadership is therefore paramount to the overall success of the BIM implementation process.

\subsection{Leadership Competencies for BIM Implementation}

A review of the extant BIM literature shows that there is uncertainty over the management and leadership terms. Top management support and commitment and leadership terms should not be used interchangeably. Supportive and committed managers may use their power to implement BIM tools and concepts, but this does not necessarily imply they are the leaders of the BIM implementation process. BIM adoption initiation can take either a top-down, middle-out, or bottom-up approach [2], meaning that BIM initiators might assume the front-line or middle management positions. BIM initiators are most likely to play a leadership role across a number of BIM implementation aspects and may initially demonstrate an informal or emerging leadership structure. Similarly, emerging leadership takes place in a BIM project context [44], illustrating the relationship between leadership and management. 
Despite the fact that emerging leadership might be more effective than appointed leadership [44], BIM leadership competencies must be further developed to improve performances. Top managers may use their formal power to support the BIM implementation process through an allocation of resources and support of those who develop the process. However, leadership does transcend the boundary of formal power [45]. Leaders are able to create an environment conducive to change through their interpersonal skills and abilities. An integrated implementation of all the BIM tools, processes, and policies is not possible without the participation of leaders who possess the BIM knowledge and behavioral competencies to influence other members and mobilize the implementation process.

BIM-related competencies can be extracted from job advertisements, experts' perceptions, Delphi study, literature, and empirical data [46]. There are myriads of competencies for BIM leadership, such as the level of education [10], and the technical [47], organizational, and generalized abilities [9]. From a technical point of view, for example, BIM leaders must possess the skills and knowledge of BIM-authoring software and model management. BIM leaders must also embody the skills to handle behavior modification and should work to change cultural aspects such as people's attitudes and habits [12].

To further discuss and identify the required competencies for BIM leaders, an assessment of the scope and definition of BIM-related roles is essential. Among all the BIM-related roles presented in the literature, most research has reached consensus on following roles: BIM manager and BIM coordinator [46,47]. In addition to these two roles, Uhm et al. in [9] extracted six other roles from recruiters' job posts: BIM project manager; director; BIM designer; senior architect; BIM mechanical, electrical, and plumbing (MEP) coordinator; and BIM technician. Though job titles may differ terminologically across diverse sources, senior roles (for instance, BIM manager, BIM coordinator, BIM leader, and BIM director) can be easily recognized within the BIM domain.

In most of these roles, leadership is considered as a critical proficiency [10]. Alreshidi et al. in [48] found that strong leaders with the capability of taking firm actions are most likely to influence BIM governance effectively. Therefore, a systematic identification and assessment of BIM leaders can help AEC organizations and projects in recruiting, training, and developing more competent leaders.

\subsection{Barriers and Enablers of BIM Implementation}

The adoption and implementation of BIM tools and concepts has gained momentum within the built environment [49]. There are, however, some barriers to BIM implementation in AEC projects and organizations. These range from a lack of contextual certainty, reluctance and resistance to change, poor technology handling, insufficient systematic and organizational support, and lack of BIM standards, knowledge, and expertise [37,50]. Although these barriers may hinder the efficient adoption and implementation of BIM, scholars have identified and developed a number of key enablers to overcome the negative impact of these impediments. Some of these key enablers are management and organizational support, cultural readiness, a continuous learning environment, individual BIM competency assessment, and BIM training and education [51]. Ozorhon and Karahan in [52] identified effective leadership as one of the most important human-related factors affecting the BIM implementation process.

\subsection{Leadership Competencies}

U.S. Fortune 500 companies rated "competent global leader" as the foremost requirement among all business needs for the future [27]. Positive leadership contributes to about $76 \%$ of success in projects, whereas negative or poor leadership contributes $67 \%$ to the failure of projects [53]. This indicates the importance of studying leadership and its related competencies. In the past, many researchers have tried to theorize leadership. Turner and Müller in [17] introduced six main schools of leadership theory as

- The trait school, 
- The behavioral or style school,

- The contingency school,

- The visionary or charismatic school,

- The emotional intelligence school,

- The competency school.

Leadership competency models, regardless of their origination, are helpful for both individuals and organizations to develop and teach leadership skills [27] and to influence followers' outcomes [54].

Conferred competencies help individuals by [27]

- Summarizing the experience and insight of seasoned leaders,

- Specifying a range of useful leader behaviors,

- Providing tools that individuals can use for their self-development, and

- Outlining a leadership framework that can be used to help select, develop, and understand leadership effectiveness.

Leadership competencies help organizations by [27]

- Openly communicating which leader behaviors are important,

- Helping to discriminate the performances of individuals,

- Linking the leader's behaviors to the strategic directions and goals of the business, and

- Providing an integrated model of leadership that is relevant across many positions and leadership situations.

Every leadership theory and model has its own competencies and style. However, Hollenbeck et al. in [27] believe "no one set, whether 15 or 20 or 180, includes all the potentially useful competencies, and even if they did, no one person has them all". Therefore, researchers have tried to intentionally optimize their set of competencies to a manageable level in order to produce more practical results (e.g., [15]).

By surveying a range of public and private organizations, Dulewicz and Higgs in [13] introduced 15 leadership competencies and three leadership styles for managers and leaders. Table 1 depicts these competencies and their accepted level for each leadership style. Since these competencies are introduced as the latest leadership school (the most developed in comparison to the former schools), they were chosen to be studied in this research. Omitting some of the competencies from this list or adding others from former schools would diminish the value of this study by creating gaps in the competencies represented. These competencies are clustered under the three groups of intellectual (IQ), emotional (EQ), and managerial (MQ). The three leadership styles are Engaging, Involving, and Goal-oriented. Originally, these styles were used for organizational change projects; however, they are appropriate for any other type of project [55]. Meng et al. in [56] pointed out that "it is the leadership competency model of IQ, MQ, and EQ that gives an integration and all-dimensional evaluation for top managers in construction organizations".

Dulewicz and Higgs in [13] described leadership styles as follows:

- Goal-oriented leadership: A style that is focused on delivering results within a relatively stable context. This is a leader-led style aligned to a stable organization delivering clearly understood results.

- Involving leadership: A style that is based on a transitional organization that faces significant but not necessarily radical changes in its business model.

- Engaging leadership: A style based on a high level of empowerment and involvement appropriate in a highly transformational context. Such a style is focused on producing radical changes with high levels of engagement and commitment. 
Table 1. Fifteen leadership competencies and three styles.

\begin{tabular}{|c|c|c|c|c|c|}
\hline \multicolumn{3}{|c|}{ Leadership Competencies } & \multicolumn{3}{|c|}{ Leadership Style } \\
\hline Group & Competency & Abbreviation & Goal-Oriented & Involving & Engaging \\
\hline \multirow{4}{*}{ Intellectual (IQ)_C1 } & 1. critical analysis and judgment & I1 & High & Medium & Medium \\
\hline & 2. vision and imagination & $\mathrm{I} 2$ & High & High & Medium \\
\hline & 3. strategic perspective & I3 & High & Medium & Medium \\
\hline & 4. engaging communication & M1 & Medium & Medium & High \\
\hline \multirow{4}{*}{ Managerial (MQ)_C2 } & 5. managing resources & M2 & High & Medium & Low \\
\hline & 6. empowering & M3 & Low & Medium & High \\
\hline & 7. developing & M4 & Medium & Medium & High \\
\hline & 8. achieving & M5 & High & Medium & Medium \\
\hline \multirow{7}{*}{ Emotional (EQ)_C3 } & 9. self-awareness & E1 & Medium & High & High \\
\hline & 10. emotional resilience & E2 & High & High & High \\
\hline & 11. motivation & E3 & High & High & High \\
\hline & 12. sensitivity & E4 & Medium & Medium & High \\
\hline & 13. influence & E5 & Medium & High & High \\
\hline & 14. intuitiveness & E6 & Medium & Medium & High \\
\hline & 15. conscientiousness & E7 & High & High & High \\
\hline
\end{tabular}

\subsection{Research Gap}

Although there is a surplus of studies related to leadership for digitally enabled systems, the systemic nature of BIM means that an examination of its own core leadership competencies is required. Moreover, there is a gap in investigating the interrelationships among the competencies of BIM leaders. Examining the interrelationships among BIM leadership competencies is crucial, given the dynamic complexity of the BIM implementation process. AEC organizations and BIM professionals lack a robust measure to seek the required competencies in the BIM leadership domain. Therefore, it is essential to develop a systematic approach to allow an evaluation of the cause-and-effect relationships among leadership competencies and their relative importance within the overall BIM context. Employing fuzzy DEMATEL and fuzzy ANP helps to elucidate the relationships among BIM leadership competencies and assist BIM leaders to concentrate on the core competencies.

\section{Research Methodology}

Leadership competencies are interrelated and cannot be analyzed independently. Moreover, these competencies do not necessarily have equal importance, and their application across different circumstances is inconsistent, especially within the context of BIM. Determination of suitable leadership competencies is vital for BIM leaders, managers, and coordinators to help establish a clear framework for evaluation and development. To gather data, a questionnaire was created and distributed among BIM experts. In this questionnaire, respondents were asked to compare the 15 leadership competencies of [13] in pairs. Figure 2 illustrates the flowchart of the research methodology.

As depicted in Figure 2, first the leadership competencies were initially extracted from the related literature, and the best competency set was chosen. In the next step, the panel of decision-makers was selected, which included BIM leaders, coordinators, and managers among whom the questionnaire was distributed. Their results were then used in the DEMATEL approach to develop the fuzzy linguistic scale that was used in the ANP approach afterwards. The main outcome of the DEMATEL phase was the causal diagram, which indicates the cause-and-effect competency groups. Following the ANP approach, the priority weights of the competencies were obtained that would consequently rank them. In the last stage, the implications of the results were suggested to improve the leadership competencies of the involved BIM leaders. 


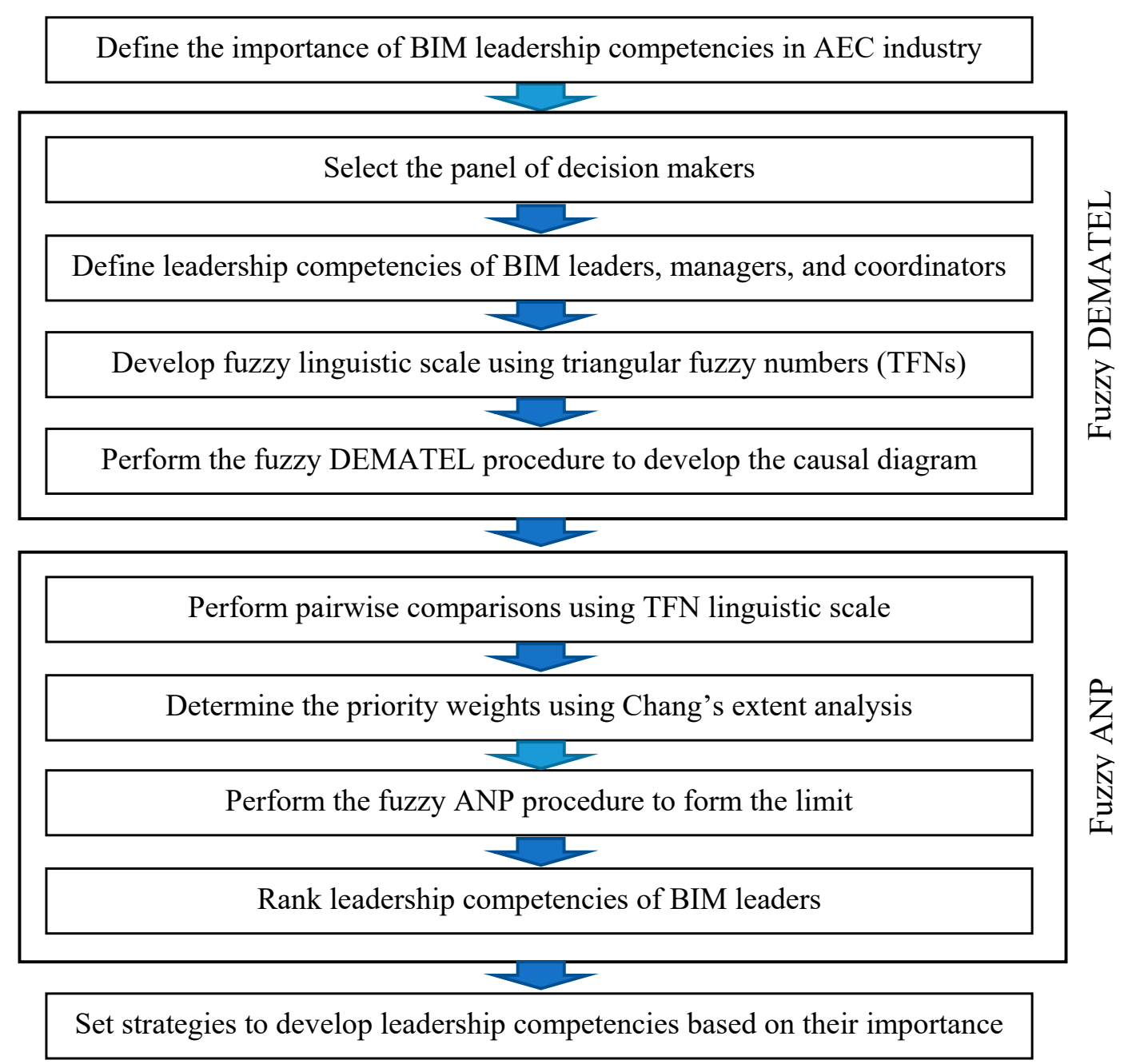

Figure 2. Generic fuzzy Decision-Making Trial and Evaluation Laboratory analytic network process (DEMATEL-ANP) framework for prioritizing BIM leadership competencies.

\subsection{Fuzzy DEMATEL}

Decision-Making Trial and Evaluation Laboratory (DEMATEL) is a well-known method for providing causal relationships between interrelated and complex factors [57]. DEMATEL can be used to clearly visualize the cause-and-effect relationships between the elements of a system [58]. Researchers have used this method in a number of diverse applications and concepts, such as transportation and traffic management [59] and supplier selection [60-62]. Chien et al. in [63] used this method to identify relationships between the critical risk factors at various levels within the context of BIM projects. In this study, Microsoft Excel 2016 was used to perform fuzzy DEMATEL analysis. The findings of the fuzzy DEMATEL method were then used as the main inputs for fuzzy ANP analysis. Fuzzy DEMATEL was performed through the following steps [28,64]:

\section{Step 1: Selecting the committee of decision-makers}

As BIM leadership roles were explained in the previous section, BIM project managers, directors, BIM designers, senior architects, BIM MEP (mechanical, electrical, and plumbing) coordinators, and BIM technicians, as well as BIM academic professionals with over five years of experience answered the survey. The questionnaires were sent to the professionals via email between 4 October and 25 November 2019. Thirty-two BIM experts, including nine academics and twenty-three professional experts, completely answered the questionnaire. The respondents were from the US (6), UK (5), 
Australia (5), Germany (3), The Netherlands (3), New Zealand (2), Sweden (2), Denmark (2), China (2), Finland (1), and Egypt (1).

Step 2: Determining factors and designing a fuzzy linguistic scale

To minimize human assessment errors, a linguistic variable should be defined. Linguistic terms, like words or sentences, define a linguistic variable. Let $\widetilde{Z}=(l, m, u)$ on $X$ is a triangular fuzzy number (TFN) where $l, m$, and $u$ denote the lower, medium, and upper values of the fuzzy numbers. Its membership function $\mu_{\widetilde{A}}(x): X \rightarrow[0,1]$ must follow Equation (1).

$$
\mu_{\widetilde{A}}(x)= \begin{cases}(x-l) /(m-l), & , \leq x \leq m \\ (u-x) /(u-m) & , m \leq x \leq u \\ 0 & , \text { otherwise }\end{cases}
$$

The five linguistic terms used in this study were "Very high," "High," Low," "Very low," and "No" influence. Table 2 shows the fuzzy scales of these linguistics. Fuzzy linguistic values and their membership function are depicted in Figure 3.

Table 2. Linguistic scales by importance.

\begin{tabular}{ccc}
\hline Linguistic Terms & Abbreviation & Linguistic Values \\
\hline Very high influence & VH & $(0.75,1.0,1.0)$ \\
High influence & $\mathrm{H}$ & $(0.5,0.75,1.0)$ \\
Low influence & $\mathrm{L}$ & $(0.25,0.5,0.75)$ \\
Very low influence & $\mathrm{VL}$ & $(0,0.25,0.5)$ \\
No influence & $\mathrm{N}$ & $(0,0,0.25)$ \\
\hline
\end{tabular}

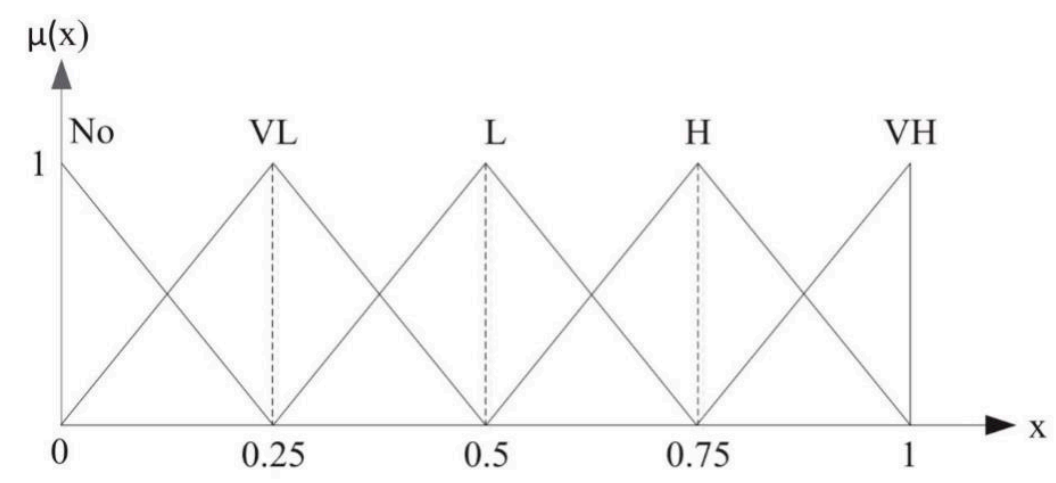

Figure 3. Fuzzy linguistic values and their membership functions [65].

Step 3: Generating the assessments of the team of decision-makers

Pairwise comparisons are obtained using fuzzy linguistic terms, they are then transformed into defuzzified numbers and aggregated as a crisp value [65]. Let $i=1,2, \ldots, n$ are $\mathrm{n}$ evaluation factors. BIM experts were asked to compare leadership competency factors in pairs to develop $\widetilde{Z}^{(1)}, \widetilde{Z}^{(2)}, \ldots, \widetilde{Z}^{(n)}$. Equation (2) shows the initial direct-relation fuzzy matrix of decision-maker $k, \widetilde{Z}^{(k)}$, in which $\widetilde{Z}_{i j}^{(\mathrm{k})}$ indicates the influence of criterion $i$ over criterion $j$ from the viewpoint of decision-maker $k$.

$$
\widetilde{Z}^{(k)}=\left[\begin{array}{ccc}
0 & \widetilde{\mathrm{Z}}_{12}^{(\mathrm{k})} & \widetilde{\mathrm{Z}}_{1 n}^{(\mathrm{k})} \\
\widetilde{\mathrm{Z}}_{21}^{(\mathrm{k})} & 0 & \widetilde{\mathrm{Z}}_{2 n}^{(\mathrm{k})} \\
\vdots & \vdots & \vdots \\
\widetilde{\mathrm{Z}}_{n 1}^{(\mathrm{k})} & \widetilde{\mathrm{Z}}_{n 2}^{(\mathrm{k})} & 0
\end{array}\right] k=1,2, \ldots, p,
$$


where $\widetilde{Z}_{i j}^{(k)}=\left(l_{i j}^{(k)}, m_{i j}^{(k)}, u_{i j}^{(k)}\right)$.

Step 4: Normalizing the direct-relation fuzzy matrix

In order to achieve the normalized direct-relation fuzzy matrix from an initial direct-relation matrix, at first, $\widetilde{\alpha}_{i}^{(k)}$ and $\beta^{(k)}$ are considered as TFNs with the values:

$$
\begin{gathered}
\widetilde{\alpha}_{i}{ }^{(k)}=\sum \widetilde{Z}_{i j}{ }^{(k)}=\left(\sum_{j=1}^{n} l_{i j}{ }^{(k)}, \sum_{j=1}^{n} m_{i j}{ }^{(k)}, \sum_{j=1}^{n} u_{i j}{ }^{(k)}\right), \\
\beta^{(k)}=\max \left(\sum_{j=1}^{n} u_{i j}{ }^{(k)}\right) \quad 1 \leq i \leq n .
\end{gathered}
$$

Linear scale transformation alters the criteria scale into comparable scales [66]. Accordingly, by normalizing the initial direct-relation fuzzy matrix, the normalized fuzzy direct-relation matrix $\widetilde{X}^{(k)}$ is obtained:

$$
\widetilde{X}^{(k)}=\left[\begin{array}{ccc}
\widetilde{\mathrm{X}}_{11}^{(\mathrm{k})} & \widetilde{\mathrm{X}}_{12}^{(\mathrm{k})} & \widetilde{\mathrm{X}}_{1 n}^{(\mathrm{k})} \\
\widetilde{\mathrm{X}}_{21}^{(\mathrm{k})} & \widetilde{\mathrm{X}}_{22}^{(\mathrm{k})} & \widetilde{\mathrm{X}}_{2 n}^{(\mathrm{k})} \\
\vdots & \vdots & \vdots \\
\widetilde{\mathrm{X}}_{n 1}^{(\mathrm{k})} & \widetilde{\mathrm{X}}_{n 2}^{(\mathrm{k})} & \widetilde{\mathrm{X}}_{n n}^{(\mathrm{k})}
\end{array}\right] ; k=1,2, \ldots, p,
$$

where $\widetilde{X}_{i j}^{(k)}=\left(\widetilde{Z}_{i j}^{(k)} / \beta^{(k)}\right)=\left(\left(l_{i j}^{(k)} / \beta^{(k)}\right),\left(m_{i j}^{(k)} / \beta^{(k)}\right),\left(u_{i j}^{(k)} / \beta^{(k)}\right)\right)$.

Presumably, there would be at least one $i$ such that $\sum_{j=1}^{n} u_{i}^{(k)}<\beta^{(k)}$. For finding the average matrix of $\widetilde{X}$, Equations (6) and (7) are used:

$$
\begin{gathered}
\widetilde{X}=\frac{\left(\widetilde{x}^{(1)} \oplus \widetilde{x}^{(2)} \oplus \ldots \oplus \widetilde{x}^{(p)}\right)}{P}, \\
\widetilde{X}=\left[\begin{array}{ccc}
\widetilde{X}_{11} & \widetilde{X}_{12} & \widetilde{X}_{1 n} \\
\widetilde{X}_{21} & \widetilde{X}_{22} & \widetilde{X}_{2 n} \\
\vdots & \vdots & \vdots \\
\widetilde{X}_{n 1} & \widetilde{X}_{n 2} & \widetilde{X}_{n n}
\end{array}\right],
\end{gathered}
$$

where $\widetilde{\mathrm{X}}_{i j}=\left(\sum_{k=1}^{p} \widetilde{x}_{i j}^{(k)} / p\right)$.

Step 5: Establishing and analyzing the structural model

In this step, the fuzzy total-relation matrix $\widetilde{T}$ is acquired by ensuring $\lim _{W \rightarrow \infty} \widetilde{T}=0$. This matrix is shown in the following Equations:

$$
\begin{aligned}
& \widetilde{T}=\lim _{W \rightarrow \infty}\left(\widetilde{X}^{1}+\widetilde{X}^{2}+\ldots+\widetilde{X}^{W}\right), \\
& \widetilde{T}=\left[\begin{array}{ccc}
\widetilde{t}_{11} & \widetilde{\mathfrak{t}}_{12} & \widetilde{\mathfrak{t}}_{1 n} \\
\widetilde{\mathfrak{t}}_{21} & \widetilde{\mathfrak{t}}_{22} & \widetilde{\mathfrak{t}}_{2 n} \\
\vdots & \vdots & \vdots \\
\widetilde{\mathfrak{t}}_{n 1} & \widetilde{\mathfrak{t}}_{n 2} & \widetilde{\mathfrak{t}}_{n n}
\end{array}\right],
\end{aligned}
$$

where $\widetilde{\mathrm{t}}_{i j}=\left(l_{i j}^{\prime \prime}, m_{i j}^{\prime \prime}, u_{i j}^{\prime \prime}\right)$.

$$
\begin{aligned}
\operatorname{Matrix}\left[l_{i j}^{\prime \prime}\right] & =X_{l} \times\left(I-X_{l}\right)^{-1} \\
\operatorname{Matrix}\left[m_{i j}^{\prime \prime}\right] & =X_{m} \times\left(I-X_{m}\right)^{-1}
\end{aligned}
$$




$$
\operatorname{Matrix}\left[l_{i j}^{\prime \prime}\right]=X_{u} \times\left(I-X_{u}\right)^{-1}
$$

Step 6: Producing the causal diagram

Vectors $\widetilde{D}_{i}$ and $\widetilde{R}_{i}$ are the sum of rows and the sum of columns, respectively, within the total-relation fuzzy matrix $\widetilde{T}$. By adding $\widetilde{D}_{i}$ to $\widetilde{R}_{i}$, the "Prominence" horizontal axis vector $\left(\widetilde{D}_{i}+\widetilde{R}_{i}\right)$ is calculated, which shows the importance of criterion $i$. This vector shows how much importance each leadership competency has. By applying Equation (11), the fuzzy numbers of vectors $\widetilde{D}_{i}$ and $\widetilde{R}_{i}$ are defuzzified into crisp values.

$$
\begin{gathered}
\widetilde{\mathbf{N}}_{\mathrm{k}}{ }^{\text {def }}=L+\Delta \times \frac{(m-L)(\Delta+u-m)^{2}(R-l)+(u-L)^{2}(\Delta+m-l)^{2}}{(\Delta+m-l)(\Delta+u-m)^{2}(R-l)+(u-L)(\Delta+m-l)^{2}(\Delta+u-m)} \\
L=\min \left(l_{k}\right), R=\max \left(u_{k}\right), \Delta=R-L .
\end{gathered}
$$

Equally, the "Relation" vertical axis vector $\left(\widetilde{D}_{i}-\widetilde{R}_{i}\right)$ is made by deducting $\widetilde{R}_{i}$ from $\widetilde{D}_{i}$. The cause-and-effect sets of the criteria are then categorized by this axis. Positive $\left(\widetilde{D}_{i}-\widetilde{R}_{i}\right)$ shows that the criterion is a "cause" factor and the negative $\left(\widetilde{D}_{i}-\widetilde{R}_{i}\right)$ shows that the criterion is the "effect" factor. Finally, the causal model is mapped by the set of $\left(\widetilde{D}_{i}+\widetilde{R}_{i}, \widetilde{D}_{i}-\widetilde{R}_{i}\right)$. Cause competencies influence the other competencies of BIM leaders, while effect competencies are more influenced by the cause competencies themselves.

\subsection{Fuzzy Analytic Network Process (ANP)}

Analytic network process (ANP) was first proposed by Saaty in $1996[67,68]$. Fuzzy ANP is a general form of fuzzy analytic hierarchy network (AHP), which is used for solving complex decision-making problems by decomposing them into a limited number of issues [69]. In an AHP, unidirectional hierarchical structures are used; however, in ANP, all of the elements and relationships are defined as one-way and two-way interactions and loops [70]. With the application of this method, intangible criteria are transformed into quantitative values that can be weighted by pairwise comparisons [71]. This method is applicable to both leadership and BIM issues. In the leadership context, Li et al. in [72] applied this method to evaluate the complex and interrelated indices of strategic leadership. In the BIM discipline, Ghannadpour et al. in [73] analyzed the influence of BIM on project management knowledge areas using a fuzzy ANP-VIKOR (Vlse Kriterijumska Optimizacija Kompromisno Resenje) approach. MATLAB package version 9.1 (R2016b) was used in this study to perform fuzzy ANP. Weighing leadership competencies by fuzzy ANP was performed through the following steps [28]:

Step 1: Forming a group of decision-makers

Like the fuzzy DEMATEL section, the same 32 experts participated in this section.

\section{Step 2: Determining leadership competencies}

By reviewing the literature on leadership competencies, as it is shown in Table 1, three main groups and 15 leadership competencies of [13] were chosen for this study.

\section{Step 3: Identifying the interdependence of criteria (and sub-criteria)}

Different criteria and their sub-criteria are interrelated in actual decision-making situations. However, this assumption in the current study added more complexity to the problem. Therefore, the interdependence of sub-criteria was assumed to be the same as their main criteria.

Step 4: Performing pairwise comparisons using TFN linguistic scale 
BIM professionals were requested to compare each pair of leadership competencies and their related sub-criteria separately. The relative importance of element $i$ over element $j$ by decision-maker $k$ is represented as $\widetilde{a}_{i j}{ }^{(k)}$. Each column of $\widetilde{A}$ is a local priority vector, which is obtained from the corresponding pairwise comparison and represents the importance of the elements in the cluster $i$ on an element in the cluster $j$; however, if there is no relationship between the clusters, the corresponding matrix is a zero matrix [72]. The geometric mean is used to aggregate the decision matrices of the committee of BIM professionals.

$$
\widetilde{A}=\left[\widetilde{a}_{i j}\right]_{n \times n}: \widetilde{a}_{i j}=\left(l_{i j}, m_{i j}, u_{i j}\right),
$$

in which

$$
l_{i j}=\left(\prod_{k=1}^{K} \mathrm{l}_{\mathrm{ij}}(\mathrm{k})\right)^{\frac{1}{n}}, m_{i j}=\left(\prod_{k=1}^{K} \mathrm{~m}_{\mathrm{ij}}(\mathrm{k})\right)^{\frac{1}{n}}, u_{i j}=\left(\prod_{k=1}^{K} \mathrm{u}_{\mathrm{ij}}(\mathrm{k})\right)^{\frac{1}{n}} .
$$

Step 5: Determining the priority weights using Chang's extent analysis

The extent analysis of [74] is used for determining the crisp value of criteria and sub-criteria weights [29]. The extent analysis method uses triangular fuzzy numbers (TFNs) as fuzzy ratios creating fuzzy preference relations and degree of possibility. These relations are used for comparing the TFNs, developing crisp priority vectors that are integrated for the provision of a final ranking [75]. The steps of this method are as follows:

Step 5.1. Equation (14) defines the value of fuzzy synthetic extent for each element $i(i=1,2, \ldots, n)$.

$$
\begin{aligned}
& \widetilde{\mathrm{S}}_{i}=\left(l_{i}, m_{i}, u_{i}\right)=\left(\sum_{j=1}^{n} \widetilde{a}_{i j}\right) \otimes\left[\sum_{i=1}^{n} \sum_{j=1}^{n} \widetilde{a}_{i j}\right]^{-1} \\
&=\left(\frac{\sum_{j=1}^{n} l_{i j}}{\sum_{i=1}^{n} \sum_{j=1}^{n} u_{i j}}, \frac{\sum_{j=1}^{n} m_{i j}}{\sum_{i=1}^{n} \sum_{j=1}^{n} m_{i j}}, \frac{\sum_{j=1}^{n} u_{i j}}{\sum_{i=1}^{n} \sum_{j=1}^{n} l_{i j}}\right) .
\end{aligned}
$$

$\widetilde{\mathrm{S}}_{i}$ shows the synthesis value of criterion $i$, and $\widetilde{a}_{i j}$ shows a triangular fuzzy number [76]. $l_{i j}, m_{i j}$ and $u_{i j}$ are given by Equation (13).

Step 5.2. The possibility degree of $\widetilde{S}_{i}=\left(l_{i}, m_{i}, u_{i}\right) \geq \widetilde{S}_{j}=\left(l_{j}, m_{j}, u_{j}\right)$ is defined as Equation (15):

$$
V\left(\widetilde{\mathrm{S}}_{i} \geq \widetilde{\mathrm{S}}_{j}\right)=\sup \left[\operatorname{Min}\left(\mu_{\widetilde{\mathrm{S}}_{\mathrm{i}}}(x), \mu_{\widetilde{\mathrm{S}}_{\mathrm{j}}}(y)\right)\right]
$$

The magnitude of the relation between the pairs of numbers $(x, y)$ is shown, which can be equivalently expressed as Equation (16):

$$
V(d)=\left\{\begin{array}{cl}
1 & , \text { if } m_{i} \geq m_{j} \\
0 & , \text { if } l_{j} \geq u_{i} \\
\frac{l_{j}-u_{i}}{\left(m_{i}-u_{i}\right)-\left(m_{j}-l_{i}\right)} & , \text { otherwise }
\end{array}\right.
$$

$d$ is the ordinate of the highest intersection point between $\mu_{\widetilde{S}_{i}}$ and $\mu_{\widetilde{S}_{\mathrm{j}}}$. For a better definition of this value, Figure 4 depicts this intersection. This figure indicates that both values of $V\left(\widetilde{S}_{i} \geq \widetilde{\mathrm{S}}_{j}\right)$ and $V\left(\widetilde{\mathrm{S}}_{j} \geq \widetilde{\mathrm{S}}_{i}\right)$ are required so as to compare $\widetilde{\mathrm{S}}_{i}$ and $\widetilde{\mathrm{S}}_{j}[77]$. 


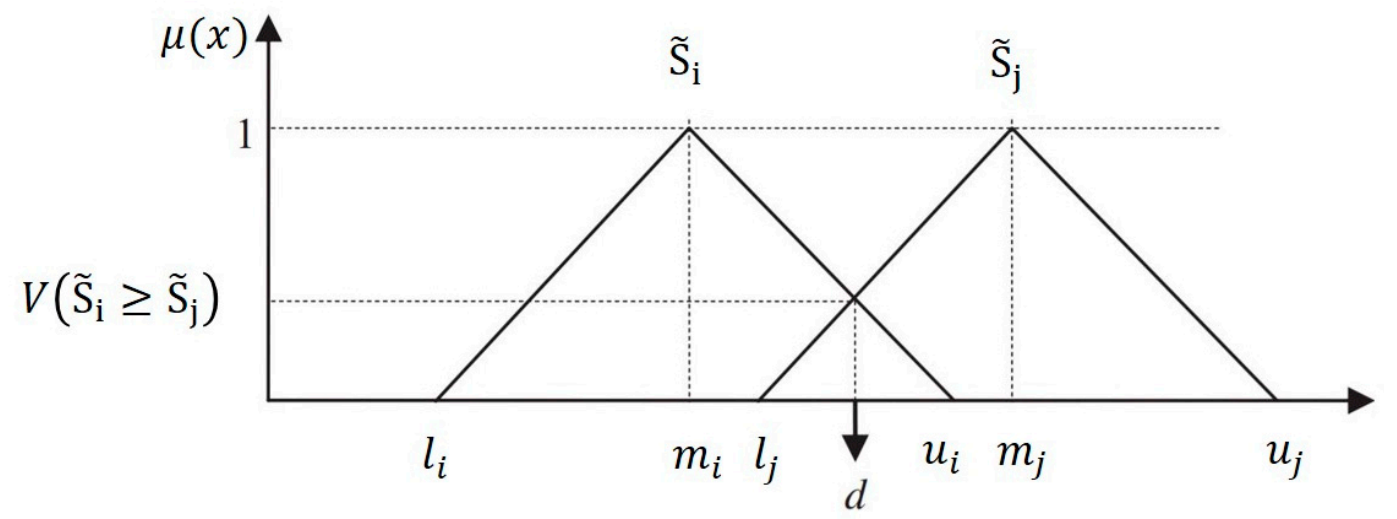

Figure 4. The intersection between $\widetilde{S}_{i}$ and $\widetilde{S}_{j}$

Step 5.3. The degree of possibility for a convex fuzzy number to be greater than all the other $n-1$ convex fuzzy numbers $\widetilde{S}_{j}(j=1,2, \ldots, n, j \neq i)$ can be defined by:

$$
\begin{gathered}
d\left(\widetilde{\mathrm{S}}_{i}\right)=V\left(\widetilde{\mathrm{S}}_{i} \geq \widetilde{\mathrm{S}}_{1}, \widetilde{\mathrm{S}}_{2}, \ldots, \widetilde{\mathrm{S}}_{i-1}, \widetilde{\mathrm{S}}_{i+1}, \ldots, \widetilde{\mathrm{S}}_{n}\right)=\operatorname{Min} V\left(\widetilde{\mathrm{S}}_{i} \geq \widetilde{\mathrm{S}}_{j}\right), \text { for } j \\
=1,2, \ldots, n, j \neq i .
\end{gathered}
$$

Step 5.4. The set $d\left(\widetilde{S}_{i}\right)$ is the weights of criteria but is not normal weights. The normalized weight vector $W=\left(w_{1}, w_{2}, \ldots, w_{n}\right)^{T}$ is calculated as Equation (18).

$$
w_{i}=\frac{d\left(\widetilde{\mathrm{S}}_{i}\right)}{\sum_{i=1}^{n} d\left(\widetilde{\mathrm{S}}_{i}\right)}, i=1,2, \ldots, n .
$$

Step 6: Form the unweighted, weighted and limit super matrices

The unweighted super matrix is composed from the computed priority weights of all criteria and sub-criteria from Step 5. After calculating the unweighted super matrix, the weighted super matrix is projected by giving equal weights to the blocks in the same column and making each column sums to unity [78]. The limit super matrix is the $2 \mathrm{~K}+1$-powered weighted super matrix, where $\mathrm{K}$ is a random large number. In this study, $2 \mathrm{~K}+1$ obtains 19 .

\section{Results and Findings}

In order to determine the interdependency between the three leadership competency groups (Table 1), fuzzy DEMATEL was applied. All of the 32 respondents had at least five years of academic or practical experience in project management (across the fields of construction engineering and management, and building information modeling). Following the steps of fuzzy DEMATEL, after obtaining the aggregated direct-relation fuzzy matrix and normalized direct-relation fuzzy matrix, the total-relation fuzzy matrix $(\mathrm{T})$ was obtained, which is depicted in Table 3. This table presents the 1 , $\mathrm{m}$, and $\mathrm{u}$ values of each group.

Table 3. Total-relation fuzzy matrix.

\begin{tabular}{cccccccccc}
\hline \multirow{2}{*}{$\mathbf{T}$} & \multicolumn{3}{c}{$\mathbf{C} 1$} & \multicolumn{3}{c}{$\mathrm{C} 2$} & \multicolumn{3}{c}{$\mathrm{C} 3$} \\
\cline { 2 - 11 } & $\boldsymbol{l}$ & $\boldsymbol{m}$ & $\boldsymbol{u}$ & $\boldsymbol{l}$ & $\boldsymbol{m}$ & $\boldsymbol{u}$ & $\boldsymbol{l}$ & $\boldsymbol{m}$ & $\boldsymbol{u}$ \\
\hline $\mathrm{C} 1$ & 0.179 & 0.343 & 0.639 & 0.191 & 0.389 & 0.712 & 0.160 & 0.355 & 0.685 \\
$\mathrm{C} 2$ & 0.160 & 0.337 & 0.664 & 0.182 & 0.361 & 0.662 & 0.144 & 0.331 & 0.669 \\
$\mathrm{C} 3$ & 0.110 & 0.276 & 0.599 & 0.150 & 0.327 & 0.639 & 0.176 & 0.342 & 0.630 \\
\hline
\end{tabular}


After calculating the total relation fuzzy matrix, the cause-and-effect values of the key competency groups were obtained. These values are represented in Table 4 . The calculated values in this table were then used to draw the causal diagram.

Table 4. The cause-and-effect values of leadership competency groups.

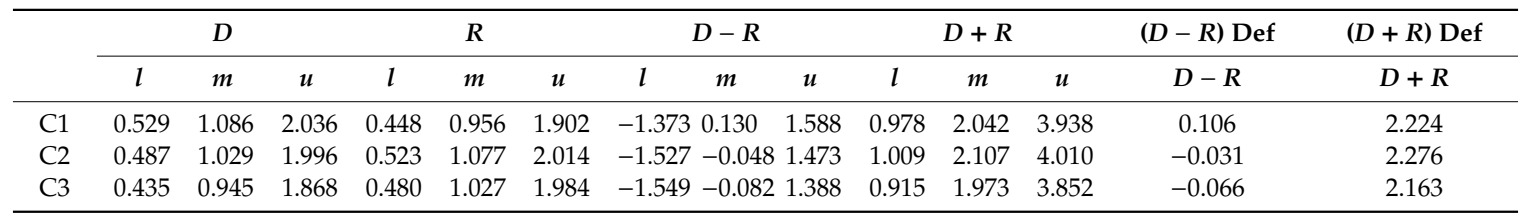

The causal diagram of leadership competency groups, based on Table 4, is delineated in Figure 5. For a realization of the cause-and-effect groups, the findings in this figure were used for drawing the relationship map.

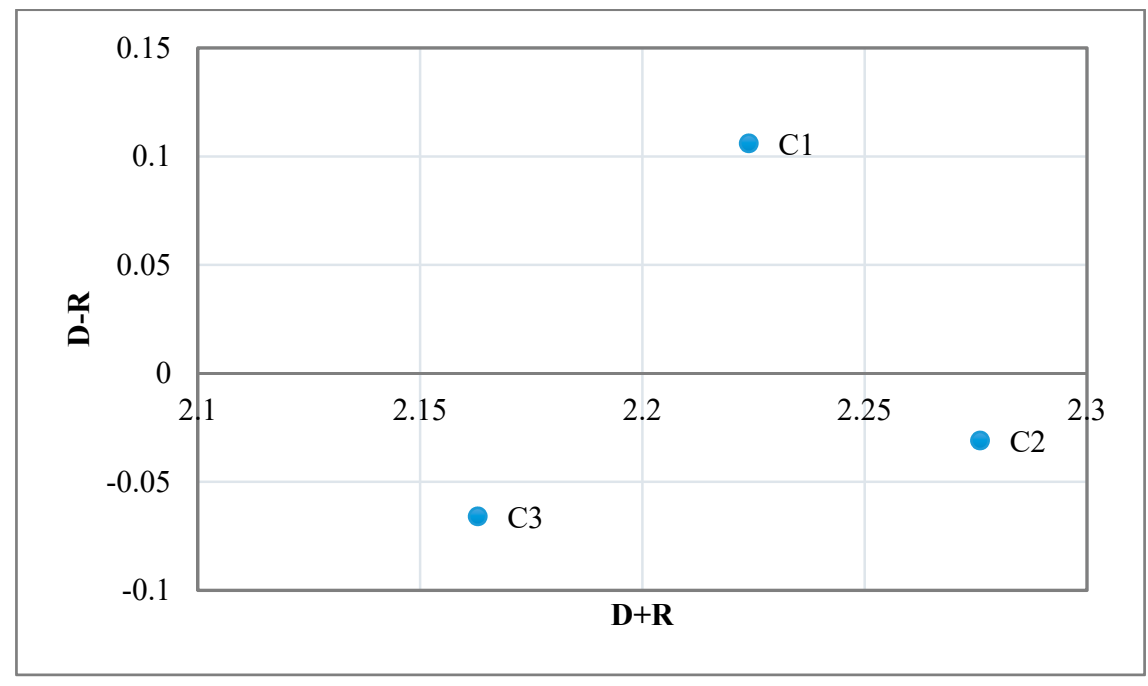

Figure 5. Causal diagram of leadership competency groups.

From the total-relation fuzzy matrix, the impact relationship map for leadership competency groups was drawn. The threshold value for the influence of criteria was the average of all the influences, which was 0.3724 . Figure 5 shows this map. Inasmuch as the influence of emotional competencies on the intellectual competencies (0.3281) was lower than the threshold value, it was ignored for further analysis. This figure shows that the intellectual and managerial groups both affected each other. The emotional group was affected by the two other groups; however, it had an inconspicuous effect on the managerial group.

Figure 6 is the input of the fuzzy ANP method. BIM professionals were asked to compare competencies and their groups in pairs. The aggregated fuzzy decision matrix (Table 5) for three competency groups was calculated using Equation (13).

Table 5. Aggregated fuzzy decision matrix.

\begin{tabular}{cccccccccc}
\hline \multirow{2}{*}{ Main Criteria } & \multicolumn{3}{c}{ C1 } & \multicolumn{3}{c}{ C2 } & \multicolumn{3}{c}{ C3 } \\
\cline { 2 - 10 } & $\boldsymbol{l}$ & $\boldsymbol{m}$ & $\boldsymbol{u}$ & $\boldsymbol{l}$ & $\boldsymbol{m}$ & $\boldsymbol{u}$ & $\boldsymbol{l}$ & $\boldsymbol{m}$ & $\boldsymbol{u}$ \\
\hline C1 & 1.0000 & 1.0000 & 1.0000 & 0.5861 & 0.8743 & 1.1481 & 0.8429 & 1.0984 & 1.2184 \\
C2 & 0.8710 & 1.1438 & 1.7062 & 1.0000 & 1.0000 & 1.0000 & 1.1838 & 1.5270 & 1.8689 \\
C3 & 0.8207 & 0.9104 & 1.1864 & 0.5351 & 0.6549 & 0.8447 & 1.0000 & 1.0000 & 1.0000 \\
\hline
\end{tabular}




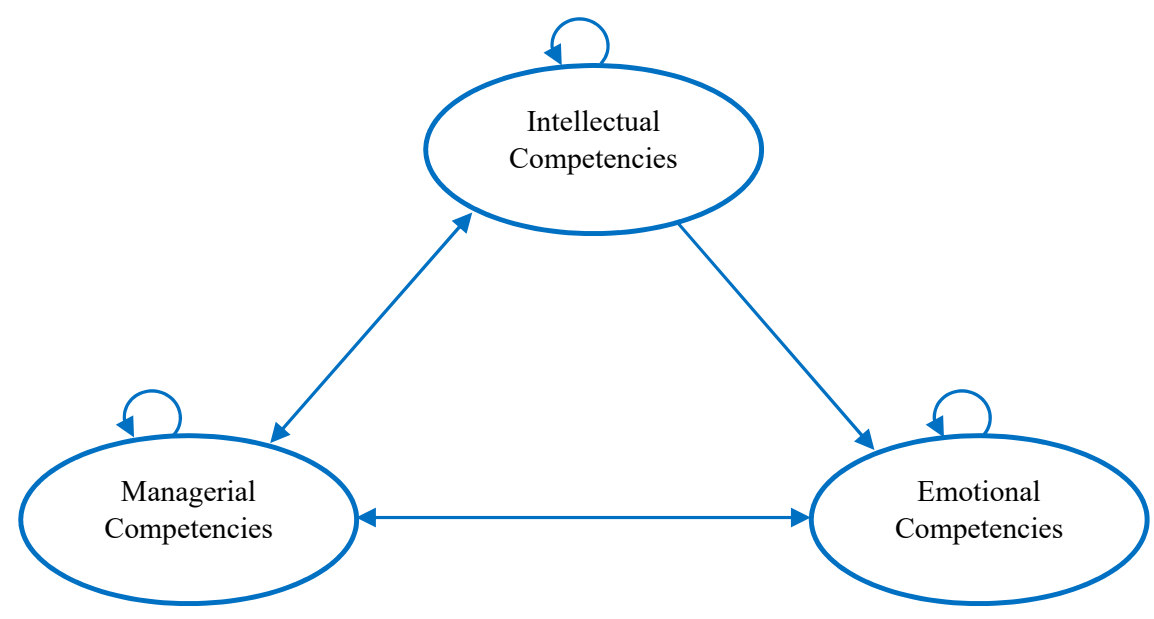

Figure 6. Impact relationship map.

Following Chang's extent analysis, the priority weights of competency groups were calculated from Equation (14):

$$
\begin{gathered}
{\left[\sum_{i=1}^{n} \sum_{j=1}^{n} \widetilde{a}_{i j}\right]=(7.8396,9.4826,10.6990),} \\
\widetilde{\mathrm{S}}_{1}=(2.4290,2.9727,3.3665) \otimes(7.8396,9.4826,10.6990)^{-1} \\
=(0.2270,0.3424,0.3945), \\
\widetilde{\mathrm{S}}_{2}=(3.0548,3.6708,4.5751) \otimes(7.8396,9.4826,10.6990)^{-1} \\
=(0.2855,0.3871,0.5836), \\
\widetilde{\mathrm{S}}_{3}=(2.3558,2.5653,3.0311) \otimes(7.8396,9.4826,10.6990)^{-1} \\
=(0.2202,0.2705,0.3866) .
\end{gathered}
$$

After obtaining priority weights of competency groups, the values of $V$, non-normalized weights of three competency groups, $d\left(\widetilde{S}_{i}\right)$, and their normalized weights, $w_{i}$, were calculated with Equations (16)-(18), respectively. The results are depicted in Table 6. The outcome of this table was used to determine the importance of the competency groups and their prioritization.

Table 6. $V$ values $\left(\widetilde{\mathrm{S}}_{\text {column }} \geq \widetilde{\mathrm{S}}_{\text {row }}\right)$.

\begin{tabular}{cccc}
\hline & $\tilde{\mathbf{S}}_{1}$ & $\tilde{\mathbf{S}}_{2}$ & $\tilde{\mathbf{S}}_{3}$ \\
\hline$\widetilde{\mathrm{S}}_{1}$ & - & 1.0000 & 0.6896 \\
$\widetilde{\mathrm{S}}_{2}$ & 0.7089 & - & 0.4645 \\
$\widetilde{\mathrm{S}}_{3}$ & 1.000 & 1.0000 & - \\
$d\left(\widetilde{\mathrm{S}}_{i}\right)$ & 0.7089 & 1.0000 & 0.4645 \\
$w_{i}$ & 0.3262 & 0.4601 & 0.2137 \\
\hline
\end{tabular}

In terms of the corresponding competency groups, all leadership competencies were compared at the second level and the decision matrices were composed. Like leadership groups, all priority weights of all competencies were calculated. First, the unweighted super matrix was composed (Table 7). Then, by normalizing it, the weighted super matrix was obtained. Finally, by raising the weighted super matrix to the power of $2 \mathrm{~K}+1$ (in this study, 19), a limited super matrix was calculated (Table 8). As this super matrix shows the weights of all competencies, considering the interdependence of their corresponding main criteria, it is meaningful for decision-makers. 
Table 7. Unweighted super matrix.

\begin{tabular}{|c|c|c|c|c|c|c|c|c|c|c|c|c|c|c|c|c|c|c|c|}
\hline & oal & C1 & 2 & C3 & I1 & I2 & I3 & M1 & M2 & M3 & M4 & M5 & E1 & E2 & E3 & E4 & E5 & E6 & E7 \\
\hline 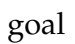 & 0000 & 0 & 0000 & 0000 & 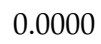 & 0000 & 0.0000 & 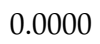 & 0.0000 & 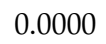 & 0 & 0.0000 & 0 & 0 & 00 & 00 & .0000 & .0000 & .0000 \\
\hline C1 & 262 & & & & & & & & & & & & & & & & & & 000 \\
\hline $\mathrm{C} 2$ & 4601 & 5437 & 4518 & 3967 & 0000 & & & 0000 & & 0000 & .0000 & .0000 & & .0000 & .0000 & & 0.0000 & .0000 & 0.0000 \\
\hline C3 & 2137 & 0000 & 2228 & 0.2618 & 0000 & .0000 & .0000 & 0.0000 & 0.0000 & .0000 & 0.0000 & 0.0000 & 0.0000 & .0000 & 0.0000 & 0.0000 & 0.0000 & .0000 & 0.0000 \\
\hline I1 & 0000 & 3269 & 0000 & 0.0000 & 0000 & & 0.3769 & 0.2845 & 0.3415 & .2948 & 0.3218 & 0.3574 & & & & & & & 0.3333 \\
\hline $\mathrm{I} 2$ & 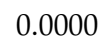 & 14 & . & 00 & & 00 & & & & & & & & & & & & & \\
\hline I3 & & 7 & & 0 & 0 & & & & & & & & & & & & & & \\
\hline M1 & & & & & & & & & & & & & & & & & & & \\
\hline M2 & & & & & & & & & & & & & & & 02 & 17 & & & 0.1134 \\
\hline $\mathrm{M}$ & & & & & & & & & & 0 & & & & & & 112 & & & 0.3027 \\
\hline M4 & & & & & & & & & & 33 & & & & & & & & & 0.1267 \\
\hline M5 & & & & 0 & & & & & & 47 & 24 & & & & & & & & 0.1986 \\
\hline E1 & & 00 & 0000 & 1 & & & 00 & & & 64 & 22 & & & & & & & & 0.1822 \\
\hline E2 & ORO & 000 & 0000 & 0 & 00 & 00 & 000 & 22 & 14 & 71 & 18 & 49 & 15 & 00 & 83 & 0.0866 & 945 & 005 & 0.1108 \\
\hline E3 & 0000 & 0.0000 & .0000 & 0.2229 & 0.0000 & 0.0000 & 0.0000 & 0.2215 & 0.2019 & 0.2011 & 0.2416 & 0.2351 & 0.2711 & 0.2863 & 0.0000 & 0.2418 & 0.2424 & 851 & 0.2415 \\
\hline E4 & 0000 & .0000 & 0000 & 0.0525 & 0.0000 & 0.0000 & 0.0000 & 0.0718 & 0.0755 & 0.0777 & 0.0512 & 0.0672 & 0.0607 & 0.0706 & 0.0890 & 0.0000 & 0.0945 & 0.0937 & 0.1024 \\
\hline E5 & 0000 & .0000 & 0000 & 0.1325 & 0000 & 0.0000 & 0.0000 & 0.1468 & 0.1288 & 0.1346 & 0.1414 & 0.1237 & 0.1437 & 0.1542 & 0.1428 & 0.1605 & 0.0000 & 0.1421 & 0.1427 \\
\hline E6 & 0 & 0000 & 0000 & 2016 & 0000 & 0.0000 & 0.0000 & 0.2416 & 0.2384 & 0.2015 & 0.2208 & 0.2234 & 0.2188 & 0.2015 & 0.2461 & 0.1722 & 0.2183 & 0.0000 & 0.2204 \\
\hline E7 & 0.0000 & 0.0000 & 0.0000 & 0.1913 & 0.0000 & 0.0000 & 0.0000 & 0.1160 & 0.1642 & 0.1916 & 0.1510 & 0.1571 & 0.2342 & 0.1690 & 0.2316 & 0.2171 & 0.1859 & 0.2013 & 0.0000 \\
\hline
\end{tabular}


Table 8. Limit super matrix.

\begin{tabular}{|c|c|c|c|c|c|c|c|c|c|c|c|c|c|c|c|c|c|c|c|}
\hline & oal & C1 & 2 & C3 & I1 & I2 & I3 & M1 & M2 & M3 & M4 & M5 & E1 & E2 & E3 & E4 & E5 & E6 & E7 \\
\hline 1 & 0000 & 0 & 0000 & 0 & DOחת & 0000 & 0.0000 & 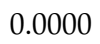 & 0.0000 & 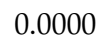 & 0 & 0 & 00 & 0 & 00 & .0000 & .0000 & .0000 & .0000 \\
\hline C1 & & & & & & & & & & & & & & & & & & & 0000 \\
\hline $\mathrm{C} 2$ & 000 & 0000 & 0000 & & & & & 0000 & & .0000 & .0000 & .0000 & & .0000 & .0000 & .0000 & 0.0000 & .0000 & 0.0000 \\
\hline C3 & 000 & 0000 & 0000 & 0000 & 0000 & .0000 & .0000 & 0.0000 & 0.0000 & .0000 & 0.0000 & 0.0000 & 0.0000 & .0000 & 0.0000 & 0.0000 & 0.0000 & .0000 & 0.0000 \\
\hline I1 & 1262 & 0.1262 & 1262 & 0.1262 & 1262 & 0.1262 & 0.1262 & 0.1262 & 0.1262 & .1262 & 0.1262 & 0.1262 & 0.1262 & 0.1262 & 0.1262 & 0.1262 & 0.1262 & & 0.1262 \\
\hline $\mathrm{I} 2$ & $15 \mathrm{G}$ & 01564 & 1564 & 0.1564 & 0.1564 & 01564 & & & & & & & & & & & & & \\
\hline I3 & & 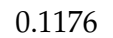 & 66 & 0 & & & & & & & & & & & & & & & \\
\hline M1 & & & & & & & & & & & & & & & & & & & \\
\hline M2 & & 70 & & & & & & & & & & 73 & & & 73 & 73 & & & 0.0373 \\
\hline M3 & & & & & & & & & & & & & & & & & & & 0.1165 \\
\hline M4 & & & & 52 & & & & & & & & & & & & & & & 0.0652 \\
\hline M5 & & 27 & & 27 & 27 & & 0.0727 & 27 & & 27 & & 0. & 0.0727 & & 0. & 0.0727 & & & 0.0727 \\
\hline E1 & 68 & 68 & 68 & 68 & 68 & 88 & 0.0 & 58 & 68 & 68 & 68 & 68 & 0. & & 0. & 68 & 68 & 68 & 0.0268 \\
\hline E2 & 15 & 0.015 & 15 & 15 & 15 & 15 & 0.015 & 15 & & 0 & & 15 & 0.015 & & 0.015 & 0. & 15 & 15 & 0.015 \\
\hline E3 & 0.043 & & 0.043 & 0.043 & & 0.043 & 0.043 & 0.043 & & 0.043 & 0.043 & 0.043 & 0.043 & & 0.043 & 0.043 & 0.043 & 0.043 & 0.043 \\
\hline E4 & 0147 & .0147 & 0147 & 0.0147 & 0.0147 & 0.0147 & 0.0147 & 0.0147 & 0.0147 & 0.0147 & 0.0147 & 0.0147 & 0.0147 & 0.0147 & 0.0147 & 0.0147 & 0.0147 & 0.0147 & 0.0147 \\
\hline E5 & 0266 & .0266 & 0266 & 0.0266 & 0.0266 & 0.0266 & 0.0266 & 0.0266 & 0.0266 & 0.0266 & 0.0266 & 0.0266 & 0.0266 & 0.0266 & 0.0266 & 0.0266 & 0.0266 & 0.0266 & 0.0266 \\
\hline E6 & 041 & 0414 & 0414 & 0414 & 0.0414 & .0414 & 0.0414 & 0.04 & 0.0414 & .0414 & 0.0414 & 0.0414 & 0.0414 & & 0.0414 & 0.0414 & 0.0414 & & 0.0414 \\
\hline E7 & 0.0325 & 0.0325 & 0.0325 & 0.0325 & 0.0325 & 0.0325 & 0.0325 & 0.0325 & 0.0325 & 0.0325 & 0.0325 & 0.0325 & 0.0325 & 0.0325 & 0.0325 & 0.0325 & 0.0325 & 0.0325 & 0.0325 \\
\hline
\end{tabular}


With the knowledge of the weight of each competency from Table 8, the most suitable leadership style could be selected for BIM leaders. First, the rate (low/medium/high) of each competency was decided on and compared to the minimum requirements of the competency profiles of the three leadership styles in Table 1 . The highest weight was 0.1564 for I2 (vision and imagination), and the lowest weight was 0.0147 for E4 (sensitivity). By subtracting the lowest weight from the highest one and dividing the result by 3 , the ranges of low, medium, and high were separated by 0.0472 . Therefore, the ranges were

$$
\begin{aligned}
& 0.0147<\text { Low }<0.0619(0.0147+0.0472) \\
& 0.0619<\text { Medium }<0.1092(0.0619+0.0472) \\
& 0.1092<\text { High }<0.1564
\end{aligned}
$$

Now, the rate for each competency was obtained. These rates are shown in Table 9. Following the abovementioned limits, the rate of each competency was calculated and compared to the three main leadership styles. This finding determined the most suitable leadership style of BIM leaders.

\begin{tabular}{|c|c|c|c|c|c|c|}
\hline \multicolumn{4}{|c|}{ Leadership Competencies } & \multicolumn{3}{|c|}{ Leadership Style } \\
\hline Group & Competency & Weight & Rate & Goal-Oriented & Involving & Engaging \\
\hline \multirow{3}{*}{ Intellectual (IQ) } & $\begin{array}{l}\text { Critical analysis } \\
\text { and judgment }\end{array}$ & 0.1262 & High & High & Medium & Medium \\
\hline & Vision and imagination & 0.1564 & High & High & High & Medium \\
\hline & Strategic perspective & 0.1176 & High & High & Medium & Medium \\
\hline \multirow{5}{*}{ Managerial (MQ) } & Engaging communication & 0.1081 & Medium & Medium & Medium & High \\
\hline & Managing resources & 0.0373 & Low & High & Medium & Low \\
\hline & Empowering & 0.1165 & High & Low & Medium & High \\
\hline & Developing & 0.0652 & Medium & Medium & Medium & High \\
\hline & Achieving & 0.0727 & Medium & High & Medium & Medium \\
\hline \multirow{7}{*}{ Emotional (EQ) } & Self-awareness & 0.0268 & Low & Medium & High & High \\
\hline & Emotional resilience & 0.015 & Low & High & High & High \\
\hline & Motivation & 0.043 & Low & High & High & High \\
\hline & Sensitivity & 0.0147 & Low & Medium & Medium & High \\
\hline & Influence & 0.0266 & Low & Medium & High & High \\
\hline & Intuitiveness & 0.0414 & Low & Medium & Medium & High \\
\hline & Conscientiousness & 0.0325 & Low & High & High & High \\
\hline
\end{tabular}

Table 9. The rates of BIM leadership competency profiles, compared to leadership styles' minimum requirements.

\section{Discussion}

\subsection{Interrelations among Competency Groups}

From Figure 5, it was concluded that the intellectual group (C1) was the cause group, and managerial (C2) and emotional (C3) groups were effect groups, which were affected by the intellectual group. The topic of competency was convoluted and not clear, especially in the cases of EQ and IQ, which were strongly overlapped [79]. However, Antonakis et al. in [80] debated that the rates of effectiveness and importance of EQ and IQ are completely context-determined, where EQ does not have predictive validity in leadership. This aligned with the findings of this survey, in which IQ was the cause and EQ was one of the effect groups specifically within the BIM context. This indicated that although EQ competencies are important, they do not directly affect the BIM leader's performance. According to the results of Table 9, it was concluded that intellectual competencies have the highest importance in comparison with the two other groups in the BIM context and that all of their rates are "high". The challenges in BIM-based projects and organizations are not wholly managerial; in many cases these challenges are, in fact, technical. Thus, improving BIM leaders' intellectual skills has a two-fold benefit. Such leaders must be on a constant lookout for new approaches and techniques to cope with any issues that may arise and to increase their advantages over other competitors. This improvement is more important than the improvement of managerial competencies as it is required for developing the roadmap of the BIM implementation and adoption process. Enhancing 
managerial competencies without giving adequate attention to the intellectual competencies will provide undesired results.

In order to develop either a BIM implementation plan in an organization or a BIM execution plan (BEP) in projects, it is important to note that the intellectual and managerial competencies of BIM leaders take precedence over the emotional competencies. When it comes to IQ competencies, intellectual stimulation is an important way of leading team members to improve their communication and creative performance [81]. More focus given to these competencies will positively affect the management of the BIM implementation process as they usually consist of complex technical and theoretical issues. The sharing of data within the BIM context is done through common data environments (CDEs), where the BIM manager is responsible for initiating collaboration among the practitioners. Inefficient data sharing (both graphical and non-graphical) in CDEs hinders the execution of BIM projects. This finding also agreed with the conclusion of [15] in which intellectual leadership competencies of project managers play the most significant role in sustainable building achievements. However, the managerial group had the highest value of $(D+R)$ among all groups, which means that the managerial competencies are more related to the whole competency profile of a BIM practitioner. BIM implementation influences work practices and relationships between practitioners, which demands high level managerial competencies in BIM leaders [82]. For executing BIM projects, leaders must manage two main requirements: managing the employer information requirement (EIR) and validating outcomes [83]. EIR consists of technical, management, and commercial areas, and its development, as well as the outcomes' validation, requires considerable knowledge and expertise. A BIM leader must be intellectually and managerially competent in order to handle these two processes. Lack of knowledge in BIM leaders (i.e., weaknesses in EQ and MQ competencies) is likely to hinder BIM implementation [84] as the necessary processes cannot be executed appropriately. Moreover, at the organizational level, it is fundamental for BIM managers to be competent enough in providing appropriate trainings and also in dispersing knowledge and information about BIM tools and concepts.

Emotional competencies (C3) were highly influenced by the two other competency groups. For instance, intuitiveness (E6), as an emotional competency, was essentially dependent on vision and imagination (I2) as an intellectual competency. If a BIM leader wants to make an apt decision with incomplete and ambiguous information (intuitiveness), he or she must be imaginative and foresee the impact of the decision (vision and imagination). McKenna et al. in [85] claimed that a wise leader has a good vision, insight, and foresight.

Comparing emotional and managerial competencies, influencing (E5) team members can be affected by empowering (M3) them. A satisfactory level of empowerment in leadership can be beneficial, humane, and virtuous [86] as it has the capacity to foster subordinates' motivation [87]. Providing staff autonomy and encouraging them to produce innovative ideas within a BIM environment (empowering) persuades them to reflect on and change their views based on their understanding of their own position (influencing). In the BIM domain, Sacks et al. in [88] examined the concept of empowerment; they developed a system that empowered BIM professionals to coordinate and negotiate better through the project life cycle.

According to Table 8, the highest weight was for managerial competencies, which means these competencies were more substantial than other competencies in the intellectual and emotional groups. Müller et al. in [23] also found that managerial competencies are correlated to a project's success. This finding of high weights of managerial and intellectual competencies was identical to the findings published in [56], which concluded that managerial and intellectual competencies directly impact the accomplishment of infrastructure sustainability. Furthermore, emotional competencies were found to moderately influence managerial competencies. "Empowering" and "vision and imagination" were described previously; other top competencies are elaborated below. 


\subsection{Intellectual Competencies}

After "vision and imagination", "critical analysis and judgment" had the highest weight among all competencies. As BIM-authoring tools enable different analyses of a project, such as structural analysis [89], BIM professionals must be competent analyzers when dealing with the outcomes of BIM models. "Strategic perspective" was third among all competencies. Since BIM experts cooperate and collaborate with different teams that might have divergent or competitive goals and expectations, possessing a precise sense of the results of members' actions is a significant competency.

\subsection{Managerial Competencies}

After "empowering," "engaging communication" had the highest weight among managerial competencies. In the BIM environment, communication plays an important role as members of different offices and teams must collaborate through a singular BIM model, and the nominated BIM leader must demonstrate this competency proficiently to manage the flow of communications and subordinates' expectations. Davies et al. in [90] also concluded that communication is a vital competence for a BIM practitioner. Willingness to collaborate and share information are BIM competencies that improve the efficiency of the overall BIM governance structure [48]. "Achieving" was the third most important managerial competency. A proficient BIM expert must be able to achieve the established goals and objectives within a BIM implementation plan. They also need to set realistic and high-performance expectations and mutually help their BIM team to achieve these. Interestingly, "managing resources" received one of the lowest weights among all BIM leadership competencies. This may be due to the fact that managing resources has been considered as a responsibility of the top management level or human resource division and is therefore not considered a competency of the BIM leadership, per se.

\subsection{Emotional Competencies}

Although the weights of emotional competencies were lower than the two other groups, there were some important competencies among them that improve BIM leaders' performance. "Motivation" had the highest weight among emotional competencies. BIM leaders must have enough energy to pursue the project's goals as well as to motivate their team to use the technology [89]. Identically, Barison and Santos in [10] realized that motivation to pursue continual learning is a required competency for BIM managers. Le et al. in [91] found that depleted motivation is one of the issues that inhibits adoption. "Intuitiveness" ranked second among the emotional competencies. In the designing phase, there are lots of ambiguities in detailing a building or structure; therefore, BIM leaders must be intuitive and able to handle this equivocalness. "Conscientiousness" refers to a commitment to pursue an ethical solution and was the third most important emotional competency as it is a strong predictor of leadership effectiveness [92]. However, as EQ was an effect group, conscientiousness-one of the competencies in this group — had an indirect influence on leadership effectiveness [93]. The integrity [9] and commitment of a BIM expert throughout a project is imperative when facing diverse challenges.

\subsection{Effective Leadership Style for BIM Leaders}

Table 9 shows that the BIM leadership competency profile fulfilled six competencies of "goal-oriented" and "engaging" leadership style, and seven competencies of "involving" style. Therefore, the closest fit in leadership style for BIM professionals was "involving," although the rates of all emotional competencies were low in comparison with these three styles. Additionally, Turner et al. in [94] found that "involving" leadership is the leadership style most often used by project managers.

In a particular BIM implementation step (evolutionary step), a project team may deal with significant but not fundamental changes in different phases of a given project. For example, since the process in the design phase is iterative, the content and structure of design information is subject to continuous change [95]. Poor change coordination may interrupt the decision-making processes in other phases of construction projects [96]. Hence, openness to change is an essential 
management factor for different stakeholders when dealing with BIM-related issues [97], as Dulewicz and Higgs [13] claimed that dealing with different levels of change (low, moderate, or high change) can be done more satisfactorily by a specific leadership style. Table 10 presents this match to each leadership style. According to this table, "involving" leadership style was a "good fit" for dealing with moderate changes.

Table 10. Matching leadership style and change context.

\begin{tabular}{cccc}
\hline \multirow{2}{*}{ Leadership Style } & \multicolumn{3}{c}{ Change Context } \\
\cline { 2 - 4 } & Low Change & Moderate Change & High Change \\
\hline Goal-oriented & Good fit & A degree of fit & - \\
Involving & A degree of fit & Good fit & A degree of fit \\
Engaging & - & A degree of fit & Good fit \\
\hline
\end{tabular}

Taking all the aforementioned results into account, it is suggested that BIM leaders develop the abilities and competencies more related to the "involving" leadership style to better deal with moderate changes throughout their projects and within their organizations. Educational and training centers can focus more on the concept of the involving leadership style and its related competencies to increase the competency of BIM leaders in developing both technical and managerial skills, such as vision and imagination, critical analysis, empowering, or communication skills, to a more acceptable level. BIM firms can also incorporate these competencies into their training and developing curricula through self-learning, workshops, in-house training, or the hiring of external and experienced personnel [98].

\subsection{Practical Implications of Leadership Competencies for Implementing BIM}

From a practical point of view, the selection and development of effective BIM leaders relies on the top IQ, MQ, and EQ competencies (as a set of criteria) and is a driving factor behind AEC projects and firms in achieving their goals. Table 11 presents the practical implications of the most significant competencies, which are elaborated as follows.

Table 11. Practical implications of significant leadership competencies in the BIM context.

\begin{tabular}{|c|c|c|}
\hline Group & Competency & Practical Implications \\
\hline \multirow{3}{*}{ Intellectual (IQ) } & Critical analysis and judgment & $\begin{array}{l}\text { Leading the project team facing complex and complicated tasks; validating the outcomes } \\
\text { of BIM implementation }\end{array}$ \\
\hline & & Judging BIM-related enablers and barriers by analyzing diverse BIM policies and tools; \\
\hline & Vision and imagination & $\begin{array}{c}\text { overseeing the development of a conductive cultural and technology-driven BIM } \\
\text { implementation and adoption; developing EIR }\end{array}$ \\
\hline \multirow{4}{*}{ Managerial (MQ) } & Strategic perspective & $\begin{array}{c}\text { Leading the changes in projects and firms by increasing members' involvement; } \\
\text { developing strategic knowledge management }\end{array}$ \\
\hline & Engaging communication & $\begin{array}{l}\text { Handling the information exchange issues; resolving conflicts; fostering collaboration } \\
\text { among diverse parties }\end{array}$ \\
\hline & Empowering & $\begin{array}{c}\begin{array}{c}\text { Empowering team members for overcoming their difficulties in learning innovative } \\
\text { novel solutions }\end{array}\end{array}$ \\
\hline & Developing & $\begin{array}{c}\text { Encouraging team members to undergo demanding accountabilities; developing } \\
\text { and maintaining strategic relations; supporting their team members to identify the most } \\
\text { crucial issues in detected clashes }\end{array}$ \\
\hline \multirow{4}{*}{ Emotional (EQ) } & Motivation & $\begin{array}{l}\text { Encouraging team members to decrease their negative attitudes toward sharing data; } \\
\text { decreasing resistance to change }\end{array}$ \\
\hline & Influence & Persuading team members to decrease their resistance to change \\
\hline & Intuitiveness & Applying consistent BIM terminologies, fostering collaboration, and removing ambiguities \\
\hline & Conscientiousness & $\begin{array}{l}\text { Not quitting when the team is facing difficulties and failures in realizing long-term } \\
\text { BIM benefits }\end{array}$ \\
\hline
\end{tabular}

Proficient BIM leaders are required to identify the needs, expectations, and competencies of the BIM members within their teams in a given situation to maximize the benefits from their BIM workflow. By focusing on these top competencies, BIM leaders are more able to improve their leadership profile across diverse situations related to the BIM context. For instance, through the lens of communication and negotiation, e-negotiation in virtual collaborations, such as automated negotiation, virtual design studios, and shared workplaces, should be considered as a key BIM leadership competency within 
AEC firms [99]. Assuming that an issue (e.g., an error in the transformation of design information) arises when using BIM-authoring technologies, it is expected that a BIM leader with a satisfactory level of "communication" competency will handle the information exchange problems, resolve the conflicts, and foster collaboration between the involved parties. Liu et al. in [44] suggested that designers and contractors often blame the coordinator for any lack of leadership when it comes to communication in design errors found in a clash detection, or when an unreasonable construction schedule is discovered. This is because the designer and contractor parties have no authority over each other. These studies clearly show the importance of "communication" and "developing" (encouraging others to take more demanding accountabilities) competencies of BIM coordinators facing challenging situations; a BIM leader with a satisfactory level of these competencies will be able to manage any controversial situation properly. To develop a BEP in BIM-based projects, managers must be able to communicate with diverse stakeholders to obtain a satisfactory Master Information Delivery Plan (MIDP). The required competencies for information sharing in this process are critical as key stakeholders (sponsors, employers, and contractors) are involved. As for producing this document, the training requirements and resource availability confirmations are developed, intellectual and managerial competencies of BIM manager, especially "communication" and "critical analysis", are required. If these competencies are lacking, processing of information in the shared environment, extracting necessary information (asset data, for instance), and determining the exchange information requirements will be executed inefficiently. High level "critical analysis and judgment" is imperative to ensure that BIM managers are knowledgeable about technical security risk tools as well as other tools and models used in their BIM-based projects, such as maturity and capability assessment tools. A BIM manager is also required to determine the range of security risks (ISO 19650-5:2020) of the BIM projects' CDEs, such as the range of threats of disrupted and corrupted information. A way of improving this competency is to regularly update and develop their technical knowledge about these tools and models.

In BIM-enabled projects, teams usually work across various offices and locations, and tend to work in silos and follow their own interests [100]. They might also face some technical issues when using BIM-authoring software [48]. Therefore, BIM leaders must develop and maintain strategic relationships with their BIM-authoring software vendors, consultants, contractors, and the external BIM community. When changes occur throughout the BIM implementation processes, leaders must adopt a "strategic perspective" to spearhead the transition smoothly. This may take the form of gradually increasing their members' involvement in change initiatives such as planning and decision-making. They must also tactically manage knowledge and the lessons learned to utilize them for further improvements. This management of changes is essential while approving, authorizing, and verifying BIM-based information. Competent BIM managers must lead their teams to analyze non-verified design data, and provide verification of the shared data among the project team. If changes occur, the leader must provide an environment where the change implications are as minimally invasive as possible.

Successful BIM implementation requires a clear shared vision that steers the direction of the involved projects [101]. In addition, complexity and complicated tasks are inherent to all BIM projects and are considered as a key issue within this context [102]. As such, a leader with unconvincing levels of "vision and imagination" and "critical analysis and judgment" is unlikely to sufficiently lead the project team. In these situations, a competent BIM leader must establish a clear and realistic BIM vision and critically appraise and judge different BIM-related enablers and barriers, including an analysis of various BIM policies (e.g., BIM standards and guidelines), tools (e.g., running and interpretation of BIM clash detection reports), and socio-technical components such as culture and teamwork in BIM-enabled projects. BIM managers and project owners must collaborate in order to develop capital expenditure (CAPEX) and operational expenditure (OPEX). For a plausible estimation of these costs, BIM managers must be analytically competent; otherwise, the success rate of their BIM-based projects will wane. In the early stages of BIM implementation, BIM managers should additionally create Visual Method Statements (VMSs) to provide a brief of risk assessment to the necessary parties requiring analysis of related situations. By improving 
this competency, a BIM manager is more able to effectively match a project's setup to the BIM contract requirements. From the perspective of "vision and imagination", it is assumed that BIM leaders are adept at overseeing the planning, strategizing, and development of a conductive cultural and technology-driven BIM implementation and are mutually able to promote the integration of BIM processes, policies, and technologies. Dakhil et al. [83] claimed that a BIM leader's vision is a critical factor in developing the EIR as a requirement of BIM implementation. They also claimed that perceived weakness in intellectual competency of judgment can hinder the process of outcome validation in BIM implementation. By improving this competency, a BIM leader is more likely to handle outcomes according to the available guidelines and standards (e.g., BSI-PAS 1192-3 and BS 1192:2007).

Resistance to change is a crucial barrier to the successful adoption and implementation of BIM [40]. In this scenario, the "influencing" and "motivation" competencies of BIM leaders are essential; a leader with strong influencing and motivation skills can persuade team members and provide a rationale for change by illustrating BIM benefits. Additionally, in times when participants form a negative attitude toward sharing data (as a BIM application barrier) [103], influencing and motivation competencies can assist BIM leaders in encouraging a collaborative work environment. By showing the benefits of BIM, they can also "motivate" subordinates to reduce or eliminate their resistance to change. This attitude is useful in developing a BIM organizational plan where BIM leaders are planning employee training (both the pre-training of new employees and the just-in-time training of current ones). By presenting the benefits of BIM and motivating their employees, BIM managers can better facilitate the adoption and implementation of BIM in their firms. In addition to their attempts to motivate the project's participants, BIM leaders themselves must be self-motivated and keen enough to learn a range of BIM-related subjects and concepts and be willing to achieve the goals and objectives established in the BIM execution plan. While the implementation of innovative approaches such as presenting a novel solution for as-built contents and components of BIM-authoring software in a project are difficult to fulfill for inexperienced BIM team members [104], a competent and strong BIM leader "empowers" team members to overcome their difficulties through creating a conducive learning environment. The "developing" competency of BIM leaders is related to identifying and resolving technical issues in BIM projects. For example, in the clash detecting process of BIM projects, too many clashes may be found, some of which may be false or duplicated clashes. A BIM leader must encourage the team to undergo the demanding task of identifying the most crucial ones.

Several ambiguities may develop along the way, and it is important to remember that this is usually inevitable in a project's life cycle. These might include legal changes, model accuracy and ownership, different perceptions, and changes in teamwork and collaboration. BIM leaders, therefore, must possess the necessary "intuitiveness" to apply consistent BIM-related terminologies [105], foster collaboration, and integrate different BIM pillars to minimize both the likelihood and extent of these ambiguities. Managing the process of BIM data dictionary development (ISO 23387-2020), which improves interoperability, requires this competency of BIM managers. Improvement of this competency is more vital when BIM managers are tasked with leading the training of new BIM software and workflows. Given that some BIM benefits may take longer to materialize, "conscientious" BIM leaders should never abandon their responsibilities when their team members either are less successful or fear the implications of failure [106].

Improvements of the abovementioned competencies influence the key stakeholders in organizations and BIM-based projects. However, this level of improvement depends on the underlying strategy of the BIM implementation and adoption process: bottom-up, top-down, or middle-out. In the top-down leadership of BIM implementation, top managers and/or their appointed BIM managers mostly influence their employees in this process by leading them and decreasing their resistance to change [107]. Moreover, as they are the primary initiators of BIM implementation, their competency improvement influences other key stakeholders, such as software vendors, BIM trainers, and BIM supervisors, as well. On the other hand, in bottom-up and middle-out BIM implementation strategies, commonly the BIM adoption and implementation is initiated by frontline employees or middle 
managers, and hence, they may be the emerging BIM leaders initially. In these two approaches, key employees and middle managers might initially and informally lead the processes of the BIM implementation, with one of their main duties being to persuade senior managers and follow up with them during the processes. Overall, apart from the direct effect on BIM leaders and employees, training, recruiting, and supervising agencies are major stakeholders who would be influenced by the improvement of these competencies.

\section{Conclusions}

Determining the necessary leadership competencies for BIM professionals, particularly those leadership roles in their projects and organizations, is fundamental to a project's overall success. Though previous studies have identified different sets of leadership competencies, the interrelations among and importance of those competencies has been largely neglected. Adopting a deductive approach, this research implemented fuzzy DEMATEL to reveal the mutual interactions among leadership competencies and to illustrate their cause-and-effect relations for BIM leaders. Findings showed that the intellectual competencies have a "cause" nature, which influences the managerial and emotional competencies such as the "effect" ones. Prioritizing those competencies using fuzzy ANP indicated that "vision and imagination", "critical analysis", and "strategic perspective" are the most important of all leadership competencies for BIM leaders. Giving priority weight to managerial and intellectual competencies should be conveyed to BIM training centers that focus on the technological aspects of BIM skills, which are not enough for training competent BIM specialists; they should have managerial-related lessons to their curricula as well.

Furthermore, a number of leadership competencies in the BIM domain were identified in this study. The findings recommended that the closest fit in leadership style for BIM professionals is "involving". This style is associated with transitional changes that stimulate significant but not necessarily fundamental alterations to business processes in an organization or project. Since BIM implementation entails the involvement and contribution of diverse stakeholders in the initial designing and planning stages of a project, this style of leadership seems the most suitable for BIM leaders to adopt. This finding also suggested that BIM leaders can gradually increase their members' involvement in change initiatives as a result of BIM adoption and implementation. This finding is well aligned with the notion that a series of transitional and evolutionary BIM steps must be followed to enhance BIM capability through gradual changes in structure, people, policies and processes.

Admittedly, an effective BIM leadership style is dependent upon a number of factors, such as the level of team competency, capability and maturity level of BIM projects, and situational factors. Therefore, future research is encouraged to be conducted in a manner that assesses BIM leadership competencies when AEC firms and projects reach higher BIM capability levels. Lastly, when referring to the research findings, caution is advised regarding the limited number of respondents involved. Most of the respondents were from countries such as the US, Australia, and the UK, where BIM implementation maturity levels are higher than in other countries. The abovementioned limitations suggest future studies should be conducted with a larger sample size and from different countries to better compare the results. Leadership competencies can also be studied in other concepts such as virtual teams and leaders and their related issues. Furthermore, a study of the concept of inequality among competent male and female BIM leaders is suggested.

Author Contributions: Conceptualization, S.A.M. and R.K.M.; Methodology, R.K.M. and N.K.M.; Supervision, R.K.M.; Writing —original draft preparation, S.A.M., N.K.M., B.A. and F.R.; Writing一review and editing, S.A.M., R.K.M. and B.A. All authors have read and agreed to the published version of the manuscript.

Funding: This research received no external funding.

Conflicts of Interest: The authors declare no conflict of interest. 


\section{References}

1. Bosch-Sijtsema, P.; Gluch, P. Challenging construction project management institutions: The role and agency of BIM actors. Int. J. Constr. Manag. 2019, 1-11. [CrossRef]

2. Succar, B.; Kassem, M. Macro-BIM adoption: Conceptual structures. Autom. Constr. 2015, 57, 64-79. [CrossRef]

3. Alizadehsalehi, S.; Hadavi, A.; Huang, J.C. From BIM to extended reality in AEC industry. Autom. Constr. 2020, 116, 103254. [CrossRef]

4. Alizadehsalehi, S.; Hadavi, A.; Huang, J.C. BIM/MR-Lean Construction Project Delivery Management System. In Proceedings of the 2019 IEEE Technology \& Engineering Management Conference (TEMSCON), Atlanta, GA, USA, 12-14 June 2019; pp. 1-6.

5. Lu, Q.; Lee, S.; Chen, L. Image-driven fuzzy-based system to construct as-is IFC BIM objects. Autom. Constr. 2018, 92, 68-87. [CrossRef]

6. Arashpour, M.; Heidarpour, A.; Akbar Nezhad, A.; Hosseinifard, Z.; Chileshe, N.; Hosseini, R. Performance-based control of variability and tolerance in off-site manufacture and assembly: Optimization of penalty on poor production quality. Constr. Manag. Econ. 2020, 38, 502-514. [CrossRef]

7. Alizadehsalehi, S.; Hadavi, A.; Huang, J.C. Virtual reality for design and construction education environment. In AEI 2019: Integrated Building Solutions-The National Agenda; American Society of Civil Engineers: Reston, VA, USA, 2019; pp. 193-203.

8. Rahman, R.A.; Ayer, S.K.; Tang, P.; Eicher, M. Building Information Modelling Skills in Construction-Related Disciplines: A Social Network and Job Advertisement-Based Comparative Analysis. Eng. Proj. Organ. J. 2017, 7. [CrossRef]

9. Uhm, M.; Lee, G.; Jeon, B. An analysis of BIM jobs and competencies based on the use of terms in the industry. Autom. Constr. 2017, 81, 67-98. [CrossRef]

10. Barison, M.; Santos, E. The competencies of BIM specialists: A comparative analysis of the literature review and job ad descriptions. In Computing in Civil Engineering (2011); American Society of Civil Engineers: Reston, VA, USA, 2011; pp. 594-602.

11. Bosch-Sijtsema, P.M.; Gluch, P.; Sezer, A.A. Professional development of the BIM actor role. Autom. Constr. 2019, 97, 44-51. [CrossRef]

12. Succar, B.; Sher, W.; Williams, A. An integrated approach to BIM competency assessment, acquisition and application. Autom. Constr. 2013, 35, 174-189. [CrossRef]

13. Dulewicz, V.; Higgs, M. Assessing leadership styles and organisational context. J. Manag. Psychol. 2005, 20, 105-123. [CrossRef]

14. Alvarenga, J.C.; Branco, R.R.; Guedes, A.L.A.; Soares, C.A.P.; da Silveira e Silva, W. The project manager core competencies to project success. Int. J. Manag. Proj. Bus. 2019, 13, 277-292. [CrossRef]

15. Tabassi, A.A.; Roufechaei, K.M.; Ramli, M.; Bakar, A.H.A.; Ismail, R.; Pakir, A.H.K. Leadership competences of sustainable construction project managers. J. Clean. Prod. 2016, 124, 339-349. [CrossRef]

16. Zhang, F.; Zuo, J.; Zillante, G. Identification and evaluation of the key social competencies for Chinese construction project managers. Int. J. Proj. Manag. 2013, 31, 748-759. [CrossRef]

17. Turner, J.R.; Müller, R. The project manager's leadership style as a success factor on projects: A literature review. Proj. Manag. J. 2005, 36, 49-61. [CrossRef]

18. Geoghegan, L.; Dulewicz, V. Do project managers' leadership competencies contribute to project success? Proj. Manag. J. 2008, 39, 58-67. [CrossRef]

19. Da Silva, F.P.; Jerónimo, H.M.; Vieira, P.R. Leadership competencies revisited: A causal configuration analysis of success in the requirements phase of information systems projects. J. Bus. Res. 2019, 101, 688-696. [CrossRef]

20. Tett, R.P.; Guterman, H.A.; Bleier, A.; Murphy, P.J. Development and content validation of a "hyperdimensional" taxonomy of managerial competence. Hum. Perform. 2000, 13, 205-251. [CrossRef]

21. Avolio, B.J.; Gardner, W.L.; Walumbwa, F.O.; Luthans, F.; May, D.R. Unlocking the mask: A look at the process by which authentic leaders impact follower attitudes and behaviors. Leadersh. Q. 2004, 15, 801-823. [CrossRef]

22. Nixon, P.; Harrington, M.; Parker, D. Leadership performance is significant to project success or failure: A critical analysis. Int. J. Product. Perform. Manag. 2012, 61, 204-216. [CrossRef] 
23. Müller, R.; Geraldi, J.; Turner, J.R. Relationships between leadership and success in different types of project complexities. IEEE Trans. Eng. Manag. 2011, 59, 77-90. [CrossRef]

24. Wei, F.; Li, Y.; Zhang, Y.; Liu, S. The interactive effect of authentic leadership and leader competency on followers' job performance: The mediating role of work engagement. J. Bus. Ethics 2018, 153, 763-773. [CrossRef]

25. Dastile, X.; Celik, T.; Potsane, M. Statistical and machine learning models in credit scoring: A systematic literature survey. Appl. Soft Comput. 2020, 91, 106263. [CrossRef]

26. Dotoli, M.; Epicoco, N.; Falagario, M. Multi-Criteria Decision Making techniques for the management of public procurement tenders: A case study. Appl. Soft Comput. 2020, 88, 106064. [CrossRef]

27. Hollenbeck, G.P.; McCall, M.W.; Silzer, R.F. Leadership competency models. Leadersh. Q. 2006, 17, $398-413$. [CrossRef]

28. Mavi, R.K.; Standing, C. Critical success factors of sustainable project management in construction: A fuzzy DEMATEL-ANP approach. J. Clean. Prod. 2018, 194, 751-765. [CrossRef]

29. Kiani Mavi, R.; Standing, C. Cause and effect analysis of business intelligence (BI) benefits with fuzzy DEMATEL. Knowl. Manag. Res. Pract. 2018, 16, 245-257. [CrossRef]

30. Abbasnejad, B.; Nepal, M.P.; Ahankoob, A.; Nasirian, A.; Drogemuller, R. Building Information Modelling (BIM) adoption and implementation enablers in AEC firms: A systematic literature review. Archit. Eng. Des. Manag. 2020, 1-23. [CrossRef]

31. Warner, K.S.; Wäger, M. Building dynamic capabilities for digital transformation: An ongoing process of strategic renewal. Long Range Plan. 2019, 52, 326-349. [CrossRef]

32. Olawumi, T.O.; Chan, D.W. An empirical survey of the perceived benefits of executing BIM and sustainability practices in the built environment. Constr. Innov. 2019, 19, 321-342. [CrossRef]

33. Olawumi, T.O.; Chan, D.W. Critical success factors for implementing building information modeling and sustainability practices in construction projects: A Delphi survey. Sustain. Dev. 2019, 27, 587-602. [CrossRef]

34. Bynum, P.; Issa, R.R.; Olbina, S. Building information modeling in support of sustainable design and construction. J. Constr. Eng. Manag. 2013, 139, 24-34. [CrossRef]

35. Santos, R.; Costa, A.A.; Silvestre, J.D.; Pyl, L. Informetric analysis and review of literature on the role of BIM in sustainable construction. Autom. Constr. 2019, 103, 221-234. [CrossRef]

36. Succar, B.; Sher, W.; Williams, A. Measuring BIM performance: Five metrics. Archit. Eng. Des. Manag. 2012, 8, 120-142. [CrossRef]

37. Eadie, R.; Browne, M.; Odeyinka, H.; McKeown, C.; McNiff, S. BIM implementation throughout the UK construction project lifecycle: An analysis. Autom. Constr. 2013, 36, 145-151. [CrossRef]

38. Murphy, M. Implementing innovation: A stakeholder competency-based approach for BIM. Constr. Innov. 2014, 14, 433. [CrossRef]

39. Slaughter, E.S. Models of construction innovation. J. Constr. Eng. Manag. 1998, 124, 226-231. [CrossRef]

40. Slaughter, E.S. Implementation of construction innovations. Build. Res. Inf. 2000, 28, 2-17. [CrossRef]

41. Succar, B. Building information modelling framework: A research and delivery foundation for industry stakeholders. Autom. Constr. 2009, 18, 357-375. [CrossRef]

42. Dossick, C.S.; Neff, G. Organizational divisions in BIM-enabled commercial construction. J. Constr. Eng. Manag. 2010, 136, 459-467. [CrossRef]

43. Ashcraft, H.W. Building information modeling: A framework for collaboration. Constr. Law. 2008, $28,5$.

44. Liu, Y.; Van Nederveen, S.; Hertogh, M. Understanding effects of BIM on collaborative design and construction: An empirical study in China. Int. J. Proj. Manag. 2017, 35, 686-698. [CrossRef]

45. Kotterman, J. Leadership versus management: What's the difference? J. Qual. Particip. 2006, $29,13$.

46. Hosseini, M.R.; Martek, I.; Papadonikolaki, E.; Sheikhkhoshkar, M.; Banihashemi, S.; Arashpour, M. Viability of the BIM manager enduring as a distinct role: Association rule mining of job advertisements. J. Constr. Eng. Manag. 2018, 144, 04018085. [CrossRef]

47. Davies, K.; Wilkinson, S.; McMeel, D. A review of specialist role definitions in BIM guides and standards. J. Inf. Technol. Constr. 2017, 22, 185-203.

48. Alreshidi, E.; Mourshed, M.; Rezgui, Y. Factors for effective BIM governance. J. Build. Eng. 2017, 10, 89-101. [CrossRef] 
49. Chan, D.W.; Olawumi, T.O.; Ho, A.M. Perceived benefits of and barriers to Building Information Modelling (BIM) implementation in construction: The case of Hong Kong. J. Build. Eng. 2019, 25, 100764. [CrossRef]

50. Tan, T.; Chen, K.; Xue, F.; Lu, W. Barriers to Building Information Modeling (BIM) implementation in China's prefabricated construction: An interpretive structural modeling (ISM) approach. J. Clean. Prod. 2019, 219, 949-959. [CrossRef]

51. Chan, D.W.; Olawumi, T.O.; Ho, A.M. Critical success factors for building information modelling (BIM) implementation in Hong Kong. Eng. Constr. Archit. Manag. 2019, 26, 1838-1854. [CrossRef]

52. Ozorhon, B.; Karahan, U. Critical success factors of building information modeling implementation. J. Manag. Eng. 2016, 33, 04016054. [CrossRef]

53. Nauman, S.; Khan, A.M.; Ehsan, N. Patterns of empowerment and leadership style in project environment. Int. J. Proj. Manag. 2010, 28, 638-649. [CrossRef]

54. Eva, N.; Robin, M.; Sendjaya, S.; van Dierendonck, D.; Liden, R.C. Servant leadership: A systematic review and call for future research. Leadersh. Q. 2019, 30, 111-132. [CrossRef]

55. Müller, R.; Turner, R. Leadership competency profiles of successful project managers. Int. J. Proj. Manag. 2010, 28, 437-448. [CrossRef]

56. Meng, J.; Xue, B.; Liu, B.; Fang, N. Relationships between top managers' leadership and infrastructure sustainability: A Chinese urbanization perspective. Eng. Constr. Archit. Manag. 2015, 22, 692-714. [CrossRef]

57. Parchami Jalal, M.; Shoar, S. A hybrid SD-DEMATEL approach to develop a delay model for construction projects. Eng. Constr. Archit. Manag. 2017, 24, 629-651. [CrossRef]

58. Fazli, S.; Mavi, R.K.; Vosooghidizaji, M. Crude oil supply chain risk management with DEMATEL-ANP. Oper. Res. 2015, 15, 453-480. [CrossRef]

59. Mavi, R.K.; Zarbakhshnia, N.; Khazraei, A. A fuzzy DEMATEL analysis of cultural variables in traffic rules violation. Int. J. Strateg. Decis. Sci. (IJSDS) 2017, 8, 69-85. [CrossRef]

60. Mavi, R.K.; Shahabi, H. Using fuzzy DEMATEL for evaluating supplier selection criteria in manufacturing industries. Int. J. Logist. Syst. Manag. 2015, 22, 15-42. [CrossRef]

61. Mavi, R.K. Green supplier selection: A fuzzy AHP and fuzzy ARAS approach. Int. J. Serv. Oper. Manag. 2015, 22, 165-188. [CrossRef]

62. Mavi, R.K.; Kazemi, S.; Najafabadi, A.F.; Mousaabadi, H.B. Identification and assessment of logistical factors to evaluate a green supplier using the fuzzy logic DEMATEL method. Pol. J. Environ. Stud. 2013, 22, 445-455.

63. Chien, K.-F.; Wu, Z.-H.; Huang, S.-C. Identifying and assessing critical risk factors for BIM projects: Empirical study. Autom. Constr. 2014, 45,1-15. [CrossRef]

64. Lin, K.-P.; Tseng, M.-L.; Pai, P.-F. Sustainable supply chain management using approximate fuzzy DEMATEL method. Resour. Conserv. Recycl. 2018, 128, 134-142. [CrossRef]

65. Akyuz, E.; Celik, E. A fuzzy DEMATEL method to evaluate critical operational hazards during gas freeing process in crude oil tankers. J. Loss Prev. Process Ind. 2015, 38, 243-253. [CrossRef]

66. Chou, Y.-C.; Sun, C.-C.; Yen, H.-Y. Evaluating the criteria for human resource for science and technology (HRST) based on an integrated fuzzy AHP and fuzzy DEMATEL approach. Appl. Soft Comput. 2012, 12, 64-71. [CrossRef]

67. Saaty, T.L. Multicriteria Decision Making: The Analytic Hierarchy Process; RWS Publ.: Pittsburgh, PA, USA, 1996.

68. Ignatius, J.; Rahman, A.; Yazdani, M.; Šaparauskas, J.; Haron, S.H. An integrated fuzzy ANP-QFD approach for green building assessment. J. Civ. Eng. Manag. 2016, 22, 551-563. [CrossRef]

69. Mavi, R.K.; Gheibdoust, H.; Khanfar, A.A.; Mavi, N.K. Ranking factors influencing strategic management of university business incubators with ANP. Manag. Decis. 2019, 57, 3492-3510. [CrossRef]

70. Mavi, R.K. Indicators of entrepreneurial university: Fuzzy AHP and Fuzzy TOPSIS Approach. J. Knowl. Econ. 2014, 5, 370-387. [CrossRef]

71. Mahdiyar, A.; Tabatabaee, S.; Durdyev, S.; Ismail, S.; Abdullah, A.; Rani, W.N.M.W.M. A prototype decision support system for green roof type selection: A cybernetic fuzzy ANP method. Sustain. Cities Soc. 2019, 48, 101532. [CrossRef]

72. Li, F.; Liu, L.; Xi, B. Evaluating strategic leadership based on the method of fuzzy analytic network process. Appl. Math. Inf. Sci. 2014, 8, 1461. [CrossRef]

73. Ghannadpour, S.F.; RezaHoseini, A.; Noori, S.; Yazdani, M. Analyzing the Influence of Building Information Modeling (BIM) on Construction Project Management Areas of Knowledge: Using a Hybrid FANP-FVIKOR Approach. Int. J. Ind. Eng. Prod. Res. 2019, 30, 57-92. 
74. Chang, D.-Y. Applications of the extent analysis method on fuzzy AHP. Eur. J. Oper. Res. 1996, 95, $649-655$. [CrossRef]

75. Biswas, A.; Kumar, S. Generalization of extent analysis method for solving multicriteria decision making problems involving intuitionistic fuzzy numbers. OPSEARCH 2019, 56, 1142-1166. [CrossRef]

76. Bulgurcu, B.; Nakiboglu, G. An extent analysis of 3PL provider selection criteria: A case on Turkey cement sector. Cogent Bus. Manag. 2018, 5, 1469183. [CrossRef]

77. Uygun, Ö.; Kaçamak, H.; Kahraman, Ü.A. An integrated DEMATEL and Fuzzy ANP techniques for evaluation and selection of outsourcing provider for a telecommunication company. Comput. Ind. Eng. 2015, 86, 137-146. [CrossRef]

78. Kang, H.-Y.; Lee, A.H.; Yang, C.-Y. A fuzzy ANP model for supplier selection as applied to IC packaging. J. Intell. Manuf. 2012, 23, 1477-1488. [CrossRef]

79. Joseph, D.L.; Jin, J.; Newman, D.A.; O’Boyle, E.H. Why does self-reported emotional intelligence predict job performance? A meta-analytic investigation of mixed EI. J. Appl. Psychol. 2015, 100, 298. [CrossRef]

80. Antonakis, J.; Ashkanasy, N.M.; Dasborough, M.T. Does leadership need emotional intelligence? Leadersh. Q. 2009, 20, 247-261. [CrossRef]

81. Boies, K.; Fiset, J.; Gill, H. Communication and trust are key: Unlocking the relationship between leadership and team performance and creativity. Leadersh. Q. 2015, 26, 1080-1094. [CrossRef]

82. Lindblad, H. Black boxing BIM: The public client's strategy in BIM implementation. Constr. Manag. Econ. 2019, 37, 1-12. [CrossRef]

83. Dakhil, A.; Underwood, J.; Alshawi, M. Critical success competencies for the BIM implementation process: UK construction clients. J. Inf. Technol. Constr. (ITcon) 2019, 24, 80-94.

84. Elagiry, M.; Marino, V.; Lasarte, N.; Elguezabal, P.; Messervey, T. BIM4Ren: Barriers to BIM Implementation in Renovation Processes in the Italian Market. Buildings 2019, 9, 200. [CrossRef]

85. McKenna, B.; Rooney, D.; Boal, K.B. Wisdom principles as a meta-theoretical basis for evaluating leadership. Leadersh. Q. 2009, 20, 177-190. [CrossRef]

86. Cheong, M.; Yammarino, F.J.; Dionne, S.D.; Spain, S.M.; Tsai, C.-Y. A review of the effectiveness of empowering leadership. Leadersh. Q. 2019, 30, 34-58. [CrossRef]

87. Biemann, T.; Kearney, E.; Marggraf, K. Empowering leadership and managers' career perceptions: Examining effects at both the individual and the team level. Leadersh. Q. 2015, 26, 775-789. [CrossRef]

88. Sacks, R.; Radosavljevic, M.; Barak, R. Requirements for building information modeling based lean production management systems for construction. Autom. Constr. 2010, 19, 641-655. [CrossRef]

89. Ahuja, R.; Sawhney, A.; Arif, M. Developing organizational capabilities to deliver lean and green project outcomes using BIM. Eng. Constr. Archit. Manag. 2018, 25, 1255-1276. [CrossRef]

90. Davies, K.; McMeel, D.; Wilkinson, S. Soft skill requirements in a BIM project team. In Proceedings of the 32nd International Conference of CIB W78, Eindhoven, The Netherlands, 27-29 October 2015; pp. 108-117.

91. Le, N.Q.; Er, M.; Sankaran, S.; Ta, N.B. Perspectives on BIM Profession of BIM Specialists and non-BIM Specialists: Case Study in Vietnam. In CIGOS 2019, Innovation for Sustainable Infrastructure; Springer: Berlin, Germany, 2020; pp. 1223-1228.

92. De Vries, R.E. Personality predictors of leadership styles and the self-other agreement problem. Leadersh. $Q$. 2012, 23, 809-821. [CrossRef]

93. Cavazotte, F.; Moreno, V.; Hickmann, M. Effects of leader intelligence, personality and emotional intelligence on transformational leadership and managerial performance. Leadersh. Q. 2012, 23, 443-455. [CrossRef]

94. Rodney Turner, J.; Müller, R.; Dulewicz, V. Comparing the leadership styles of functional and project managers. Int. J. Manag. Proj. Bus. 2009, 2, 198-216. [CrossRef]

95. Langroodi, B.P.; Staub-French, S. Change management with building information models: A case study. In Construction Research Congress 2012: Construction Challenges in a Flat World; American Society of Civil Engineers: Reston, VA, USA, 2012; pp. 1182-1191.

96. Kalasapudi, V.S.; Tang, P.; Turkan, Y. Computationally efficient change analysis of piece-wise cylindrical building elements for proactive project control. Autom. Constr. 2017, 81,300-312. [CrossRef]

97. Chan, I.; Liu, A.; Chen, B. Management strategies for 5D-BIM adoption in Hong Kong. In Proceedings of the 21st International Symposium on Advancement of Construction Management and Real Estate; Springer: Berlin, Germany, 2018; pp. 1023-1039. 
98. Ku, K.; Taiebat, M. BIM experiences and expectations: The constructors' perspective. Int. J. Constr. Educ. Res. 2011, 7, 175-197. [CrossRef]

99. Rahmawati, Y.; Utomo, C.; Zawawi, N.A.W.A. BIM and E-Negotiation Practices in AEC Consulting Businesses. Sustainability 2019, 11, 1911. [CrossRef]

100. Oraee, M.; Hosseini, M.R.; Edwards, D.J.; Li, H.; Papadonikolaki, E.; Cao, D. Collaboration barriers in BIM-based construction networks: A conceptual model. Int. J. Proj. Manag. 2019, 37, 839-854. [CrossRef]

101. Abbasnejad, B.; Nepal, M.; Drogemuller, R. Key enablers for effective management of BIM implementation in construction firms. In Proceedings of the CIB World Building Congress 2016: Volume I-Creating Built Environments of New Opportunities; TUT-Tampere University of Technology: Tampere, Finland, 2016; pp. 622-633.

102. Saka, A.B.; Chan, D.W. Profound barriers to building information modelling (BIM) adoption in construction small and medium-sized enterprises (SMEs). Constr. Innov. 2020, 20, 261-284. [CrossRef]

103. Zhou, Y.; Yang, Y.; Yang, J.-B. Barriers to BIM implementation strategies in China. Eng. Constr. Archit. Manag. 2019, 26, 554-574. [CrossRef]

104. Migilinskas, D.; Popov, V.; Juocevicius, V.; Ustinovichius, L. The benefits, obstacles and problems of practical BIM implementation. Procedia Eng. 2013, 57, 767-774. [CrossRef]

105. Abbasnejad, B. Building Information Modelling Adoption and Implementation in Construction Firms: A Multi-Stage Model. Ph.D. Thesis, Queensland University of Technology, Brisbane, Australia, 2018.

106. Hua, Y. The Role of Innovation Culture in BIM Diffusion in Construction: Case Studies of Chinese Construction Firms. In Proceedings of the Pacific Association of Quantity Surveyors Congress, Hong Kong, China, 7-10 June 2014; pp. 277-287.

107. Zahrizan, Z.; Ali, N.M.; Haron, A.T.; Marshall-Ponting, A.; Abd, Z. Exploring the adoption of Building Information Modelling (BIM) in the Malaysian construction industry: A qualitative approach. Int. J. Res. Eng. Technol. 2013, 2, 384-395.

(C) 2020 by the authors. Licensee MDPI, Basel, Switzerland. This article is an open access article distributed under the terms and conditions of the Creative Commons Attribution (CC BY) license (http://creativecommons.org/licenses/by/4.0/). 